Journal Article

\title{
Crack growth: Does microstructure play a role
}

Jones, R., Singh Raman, R. K. and McMillan, A. J.

This article is published by Elsevier. The definitive version of this article is available at:

https://www.sciencedirect.com/science/article/pii/S0013794417309670

\section{Recommended citation:}

Jones, R., Singh Raman, R. K. and McMillan, A. J. (2017), 'Crack growth: Does microstructure play a role?' Engineering Fracture Mechanics, vol. 187, pp.190-210. doi: 10.1016/j.engfracmech.2017.11.023 


\title{
CRACK GROWTH: DOES MICROSTRUCTURE PLAY A ROLE?
}

\author{
R. Jones ${ }^{1,2}$, R. K. Singh Raman ${ }^{1}$ and A. J. McMillan ${ }^{2}$ \\ ${ }^{1}$ Centre of Expertise for Structural Mechanics, Department of Mechanical and Aerospace \\ Engineering, Monash University, P.O. Box 31, Monash University, Victoria, 3800, Australia. \\ ${ }^{2}$ School of Applied Sciences, Computing and Engineering, Wrexham Glyndwr University, \\ Mold Road, Wrexham, LL11 2AW, Wales, UK. \\ * Corresponding author: raman.sungh@monash.edu \\ Full Name: $\quad$ R. K. Singh Raman \\ Address: $\quad$ Department of Mechanical and Aerospace \\ Engineering, Monash University, P.O. Box 31, Monash University, Victoria, 3800, Australia. \\ Email: raman.singh@monash.edu \\ Tel: $\quad 61-3-99053671$
}

\begin{abstract}
The experimental data presented in this paper reveals that even if the growth of long cracks in two materials, with different microstructures, have different $d a / d N$ versus $\Delta K$ curves the corresponding small crack curves can be similar. We also see that long cracks in a large range of steels with different microstructures, chemical compositions, and yield stresses can have similar crack growth rates. The materials science community is challenged to explain these observations. The experimental data also suggests that the threshold term $\Delta K_{\text {thr }}$ in the Hartman-Schijve variant of the NASGRO crack growth equation appears to have the potential to quantify the way in which small cracks interact with the local microstructure. In this context it is also noted that the variability in the life of operational aircraft is controlled by the probability distribution associated with the size and nature of the material discontinuities in the airframe rather than the probability distribution associated with the scatter in the growth of small cracks with a fixed initial size.
\end{abstract}

Keywords: aircraft sustainment; lead cracks; micro-structure; chemical composition; small cracks 


\section{INTRODUCTION}

Classical metallurgical engineering literature is laden with the science and technology of microstructural design of alloys and metals to enhance their strength and to achieve effective resistance to growth of an existing crack. Metallurgical engineers have been improving the strength of various engineering alloys by thermo-mechanical treatments to bring about the required changes in microstructures, such as by the refinement of grain size, by mechanical working for developing strained crystal structure or by developing suitable precipitates in the alloy microstructure. The classical metallurgy text book examples showing the profound role of microstructure in strengthening include: martensitic microstructure of steels that have extremely high hardness; precipitation hardening of aluminium through alloying with copper that caused sufficient specific strengthening and enabled the first ever flight by Wright brothers in early 1900s; and anisotropy of microstructure of an extruded aluminium alloy that causes considerable differences in strength along the extrusion and perpendicular directions. The very title of an article whether microstructure plays a role in crack growth may sound absurd to a metallurgical researcher or engineer: whilst the role of microstructure in the growth of long cracks is clearly undeniable it is shown [1] that $d a / d N$ versus $\Delta K$ curves can provide a pragmatic and reliable method of assessment. In particular, [1] revealed that the $d a / d N$ versus $\Delta K$ data associated with the growth of long cracks in five different bridge steels, lay on a single "master curve". These steels had a range of different chemical compositions and yield stresses that varied from between approximately $250 \mathrm{MPa}$ up to approximately $800 \mathrm{MPa}$ Furthermore, this bridge steel $d a / d N$ versus $\Delta K$ "master curve" coincided with that seen for the high strength aerospace steel 4340 which has a yield of approximately $1500 \mathrm{MPa}$, see Fig. 1. The bridges steels shown in Fig. 1 are:

i) A36, where the crack growth data was taken from [2,3], which is common in older bridges.

ii) HPS 485W a high performance bridge steel used in North American bridges [4].

iii) HPS 350WT a high performance bridge steel with an improved low temperature performance [4].

iv) A588-80A [4], a weathering steel that is widely used in bridges. This steel has little R ratio dependency, see [5].

v) The Chinese bridge steel $14 \mathrm{MnNbq}[6]$. 
The 4340 steel crack growth $d a / d N$ versus $\Delta K$ data is from [7].

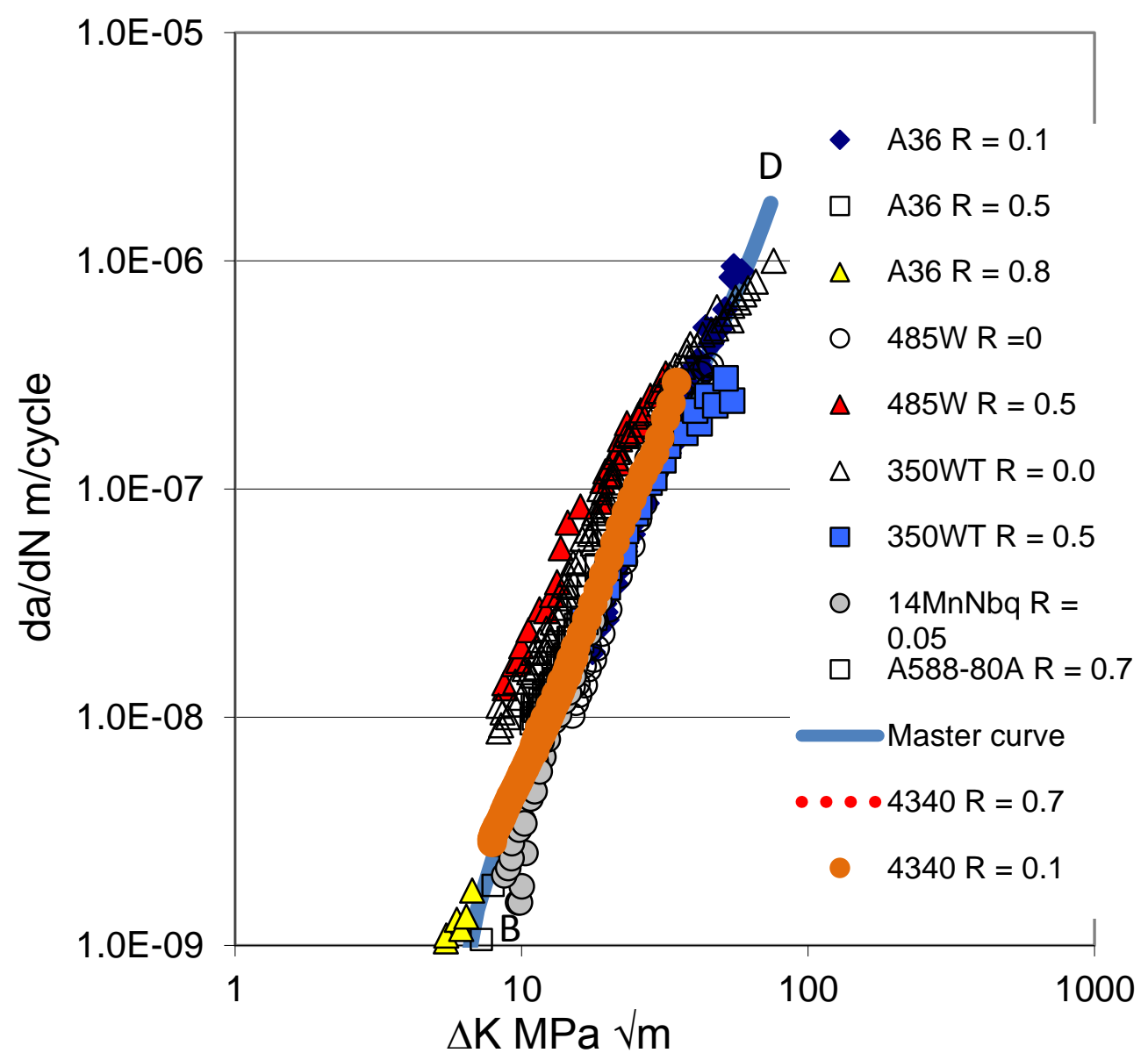

Fig. 1. Representation of the growth of long cracks in a range of bridge steels, from [1].

Ali et al [1] also revealed that the $d a / d N$ versus $\Delta K$ curves for the five cast steels 0030 , 0050A, 8630 and a C-Mn and a Mn-Mo steel were also very similar to the master curve, which is labelled B-D, shown in Fig. 1 for the bridge steels and the aerospace steel 4340, see Fig. 2. Details on the heat treatments and chemical composition of these different steels are given in [8]. The yield stress associated with these five cast steels varied from approximately $300 \mathrm{MPa}$ for 0300 steel to approximately $1000 \mathrm{MPa}$ for the 8630 steel. 


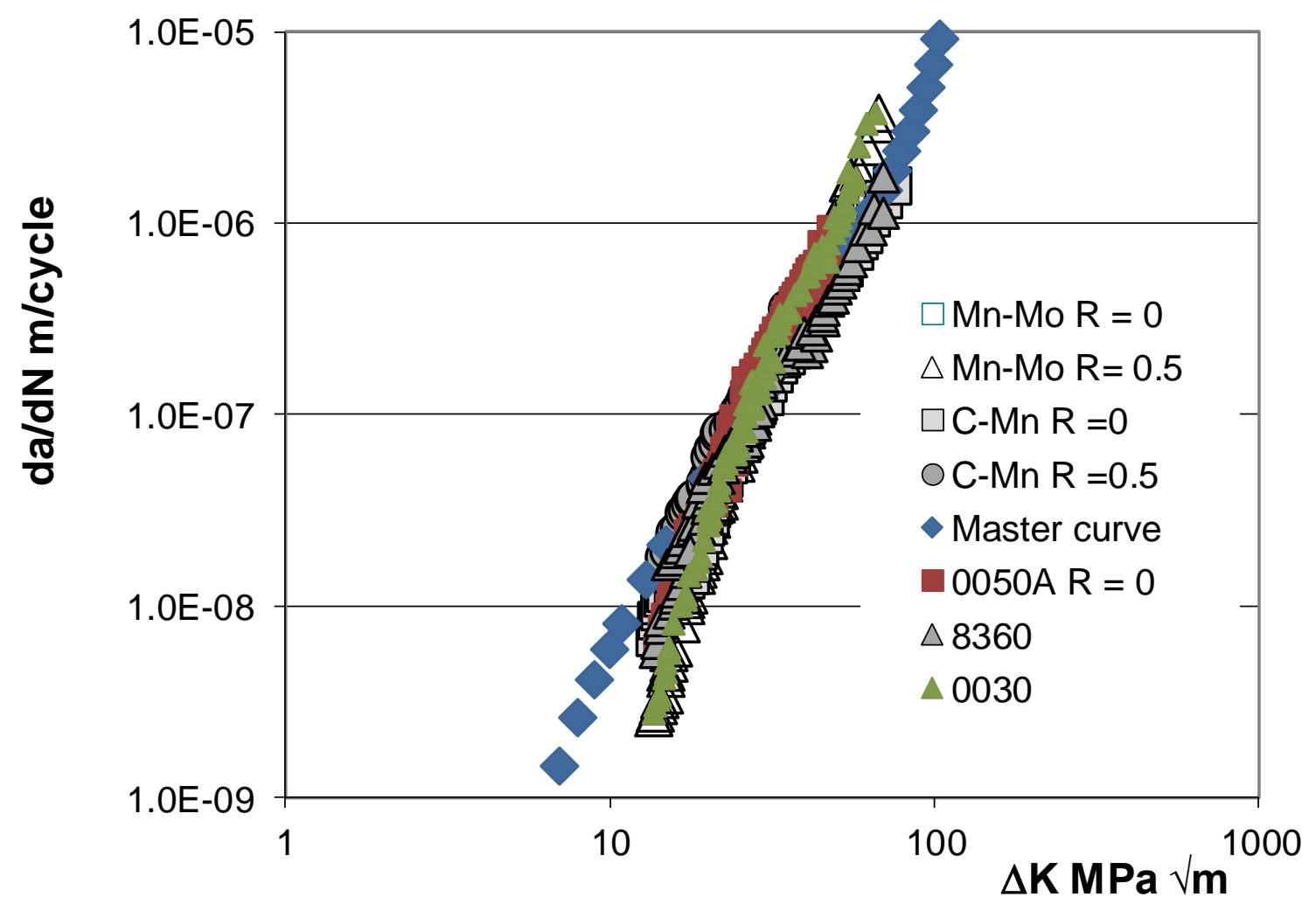

Fig. 2. Comparison of the bridge steel curve BCD with the cast steel crack growth data taken from [1].

It was thus shown that the crack growth in these eleven different steels was largely independent ${ }^{1}$ of the microstructure, chemical composition and the yield stress. As such the primary question addressed in this article is the extent to which it is helpful to consider the role of microstructure in the assessment of fatigue crack growth in operational aircraft where the growth of small "lead" cracks is of prime interest. Here it should be noted that in this paper we have essentially adopted the small crack definition contained in the fatigue test standard ASTM E647-13a "Standard Test Method for Measurement of Fatigue Crack Growth Rates" [10], albeit limited to a maximum crack length of approximately $0.04 \mathrm{~mm} \mathrm{[11],} \mathrm{see}$ Appendix.

\footnotetext{
${ }^{1}$ That said it should be noted that small discrepancies in the crack growth rate curve could lead to non-negligible differences in the fatigue lifetimes.
} 


\section{THE ROLE OF CHEMICAL COMPOSITION, HARDNESS AND YIELD STRESS ON CRACK GROWTH IN OPERATIONAL AIRCRAFT}

In this section, which primarily focuses on the problem of aircraft sustainment, we will examine two hypotheses:

i) Hypothesis 1: "Fatigue crack growth is strongly dependent on the micro-structure of a material."

ii) Hypothesis 2: "Fatigue crack growth is strongly dependent on the chemical composition and yield stress"

As a result of this study we reveal that small cracks in materials with different microstructures can have similar crack growth rates and often exhibit a $d a / d N$ versus $\Delta K$ curve that resembles a simple Paris crack growth equation. We show that both long and small cracks in materials with different chemical compositions or yield stresses can have similar crack growth rates.

In this context we show that the effect of the different microstructures on crack growth and the way in which these different microstructures effect the growth of both long and small cracks can often be captured by allowing for changes in the threshold term $\left(\Delta K_{\mathrm{thr}}\right)$ in the Hartman-Schijve variant of the NASGRO crack growth equation [12]. In this context we will show that $\Delta K_{\text {thr }}$ can be thought of as a means of (approximately) quantifying the way in which small cracks interact with the local microstructure.

\subsection{Crack growth in operational structures}

Whilst changes in microstructure can have a significant effect both on fracture toughness [13] and on the growth of long cracks tested in accordance with the ASTM fatigue test standard E647-13a [10] it has long been known [14-16] that the $d a / d N$ versus $\Delta K$ curves associated with aluminium alloys are remarkably similar. The precise words used in [16] were:

"In examining fatigue crack growth rate curves for many materials exhibiting very large differences in microstructure, the striking feature is the similarities between these curves, not the differences." 
It is also known [1] that the $d a / d N$ versus $\Delta K$ curves associated with a wide range of bridge steels and the high strength aerospace steels D6ac and 4340 essentially coincide, i.e. that the $d a / d N$ versus $\Delta K$ curves are not overly affected by the chemical composition or the yield stress. Indeed, when discussing the growth of fatigue cracks in bridge steels the US Department of Transportation Federal Highway Administrations report [17] states:

"The insignificance of steel type and weld metal on fatigue resistance greatly simplifies the development of fatigue design rules since it eliminates the need to generate data for every type of structural steel."

Regardless of whether we are talking about aircraft [12, 18-23] , or steel bridges [24, 25], it is now thought that the majority of the life is consumed in what is commonly referred to as Regions I and II of the Paris crack growth curve where the effect of toughness on crack growth is relatively small. Furthermore, the operational life is governed by the growth of (small) lead cracks, i.e. the fastest cracks in the structure which invariably start to grow shortly after the aircraft/bridge is introduced into service [12, 18-23, 26-30]. In this context it is now believed [12, 26-28] that, for a given (small) crack size, the variability in fatigue life associated with small cracks is often essentially controlled by the variability in the small crack growth rate. As a result this section of the paper will focus on the growth of small cracks. As explained in the Appendix in this paper we will adopt the Ritchie, Yu, Blom and Holm [11] definition of small, viz: less than 400 microns, rather than those contained in either the USAF Damage Tolerant Design Handbook [31] which suggests a significantly larger upper limit or the ASTM E647-13a definition which is less quantitative.

Ritchie, Yu, Blom and Holm [11] were also one of the first to reveal that for cracks that grow from small naturally occurring material discontinuities:

i) The fatigue threshold is very low. The precise wording used in [11] is "microstructurally small cracks propagate, without evidence of a threshold". This observation is consistent with statements made in Appendix X3 of the fatigue test standard E647-13a, which questions the existence of a fatigue threshold for small cracks.

ii) Ritchie, Yu, Blom and Holm [11] also stated: "Once crack closure has been subtracted out, somewhat better correspondence is achieved between long and small crack results". 
Jones [12] subsequently explained that by this [11] meant that the $d a / d N$ versus $\Delta K$ relationship associated with the growth of cracks from small naturally occurring defects can be obtained from long crack data by removing the effect of crack closure and other crack tip shielding effects.

It has long been known [32-34] that the fractal box dimension D, which is a measure of surface roughness associated with small cracks, is relatively insensitive to microstructure. This suggests that the $d a / d N$ versus $\Delta K$ relationship for such small cracks may also be relatively independent of the microstructure. The role of microstructure on the $d a / d N$ versus $\Delta K$ relationship associated with such small cracks is discussed in $[9,26,37,38]$. This led [9] to conclude:

"The changes in $\gamma^{\prime}$ morphology achieved here did not affect the rate of short crack growth in Astroloy and, apparently, for equal grain sizes, the volume fraction of $\gamma^{\prime}$, controlled by either heat treatment or alloy chemistry, also appears to have little influence."

"This observation, coupled with the small effect of grain size on short crack growth rates, seems to indicate a insensitivity to microstructure in this regime, making it hard to produce significant changes in fatigue resistance of nickel base superalloys."

Related statements on the insensitivity of the crack growth rate associated with small cracks to microstructure are contained in $[26,37,38]$. These independent statements appear to be consistent with the fact that for small cracks the fractal box dimension is essentially microstructure invariant.

These various examples reveal that the statement:

"Fatigue crack growth is strongly dependent on the micro-structure of a material" is false.

Here it should be stressed that this does not mean that there will not be instances when the growth of lead cracks in an operational structure is dependent on the micro-structure, just that this dependency can't be assumed. Furthermore, as noted in [26], for with a fixed initial 
(small) crack size the scatter in the growth would appear to be as a result of the interaction of the crack with the local microstructure. In this context [12, 23, 27, 28, 39-43] have shown that this scatter can be captured by allowing for variability in the threshold term term $\Delta K_{\mathrm{thr}}$ in the Hartman-Schijve variant of the NASGRO crack growth equation. It should also be noted that for operational aircraft the operational life is determined by the growth of (small) lead cracks [18] which essentially grow from day one $[12,19-23,28]$ and for which, as explained in ASTM 647-13a and $[12,26,28]$ threshold effects are very small.

\subsection{Chemical composition, yield stress and hardness}

Let us next address the role of chemical composition and yield stress on crack growth. In this context, Figures 1 and 2 reveal that for the eleven different steels considered crack growth was largely independent of the chemical composition and the yield stress for all of these various steels. These various examples reveal that the statement: "Fatigue crack growth is strongly dependent on the chemical composition and the yield stress" is false. Here it should again be stressed that this does not mean that there will not be instances when the growth of lead cracks in an operational structure is dependent on chemical composition and the yield stress, just that this dependency can't be assumed.

\subsection{Representation of crack growth in operational structures}

The realisation that these two hypotheses are disproved begs the question of how to model or represent crack growth in an operational structure? The form of the $d a / d N$ versus $\Delta K$ relationship for small lead cracks can often be approximated by the curve ABD in Fig. 3, see $[38,44]$. This form of the small crack representation is discussed in detail in $[1,12,23,27,28]$ and similar curves can be seen in $[26,44,45]$. This curve contrasts with the $d a / d N$ versus $\Delta K$ curve as determined via test procedures outlined in the main body of E647-13a results, which can generally be represented by a curve of the form CBD shown in Fig. 3. 


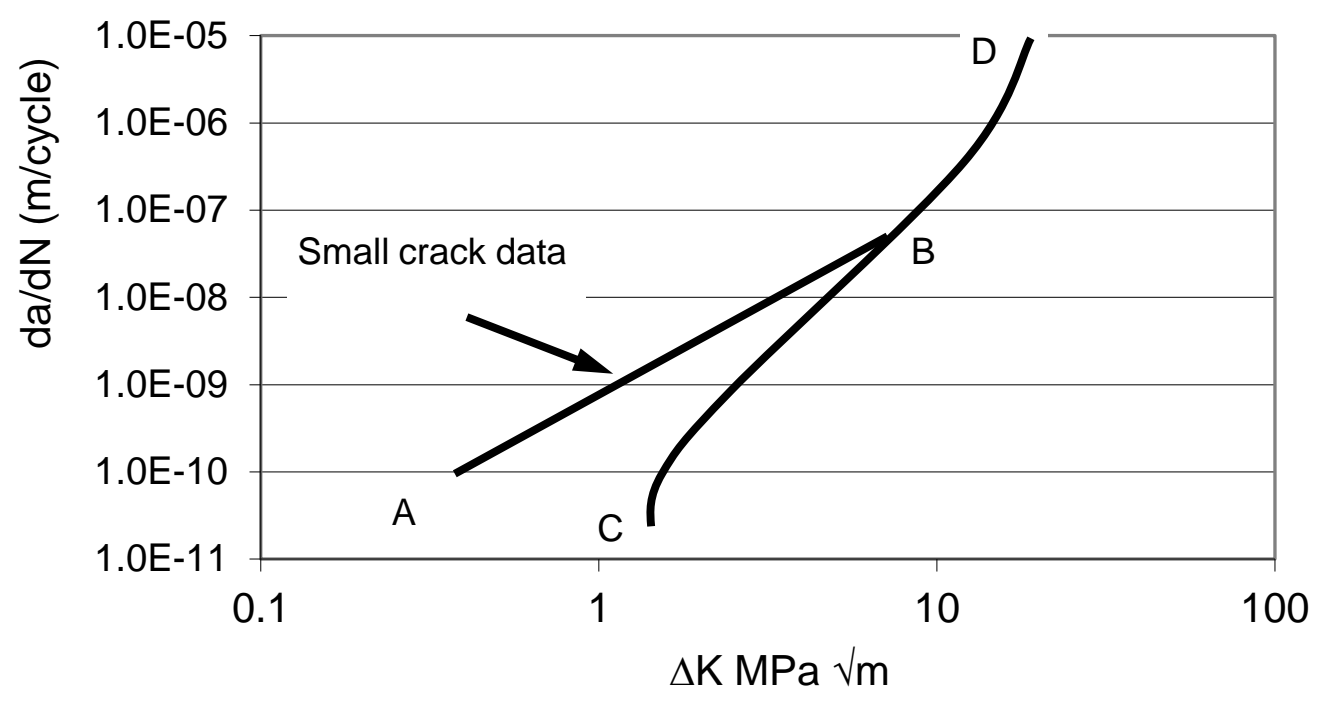

Fig. 3. Comparison of the small (lead) crack $d a / d N$ versus $\Delta K$ curves and that determined in accordance with ASTM E647-13a, from [23].

The need to work with the small crack $d a / d N$ versus $\Delta K$ curve rather than the corresponding ASTM long crack curve was one of the primary conclusions reached by USAF-McDonnell Douglas (now Boeing), following their study into sustainment issues associated with cracking in F-15 aircraft [44]. This is discussed in detail in the "state of the art" review [12]. References [12, 23, 27, 28, 39-43] also reveal that the growth of such small cracks, including the way in which multiple collocated small cracks grow and interact [46], can be captured using the Hartman-Schijve variant of the NASGRO equation:

$$
\frac{d a}{d N}=D\left[\frac{\Delta K-\Delta K_{\mathrm{thr}}}{\sqrt{1-\frac{K_{\max }}{A}}}\right]^{p}
$$

where $a$ is the crack length/depth, $N$ is the number of cycles, $D$ is a material constant, $p \approx 2$ is another constant, $A$ is the cyclic fracture toughness, $K$ is the stress intensity factor, $\Delta K=$ ( $\left.K_{\max }-K_{\min }\right)$ is the range of the stress intensity factor seen in the cycle, and $\Delta K_{\mathrm{thr}}$ is the "effective fatigue threshold". The terms $\Delta K_{\mathrm{thr}}$ and $A$ are best interpreted as parameters chosen so as to fit the measured $d a / d N$ versus $\Delta K$ data [12]. This approach has also been shown to hold for the growth of small cracks in bridge steels [12] and a link to fractal based crack growth equations is discussed in [34, 47]. 
The origin of equation (1) can be traced back to Hartman-Schijve [48]. In the derivations of similar equations, the difference lies in the form of the denominator [49, 50]. Variants of equation (1) that relate $d a / d N$ to $\left(\Delta K-\Delta K_{\text {thr }}\right)$ have been also developed and validated for the growth of both long and small cracks, by McEvily et al [51-53], as well as in [54].

As mentioned in Section 2.1 the examples discussed in this study support the conclusions arising from $[9,26,37,38]$ that micro-structural effects on the growth of small cracks can often be relatively small; nevertheless, differences in microstructures can result in quite different long crack behaviour. As such it would appear questionable to use ASTM tests to rank the effect of different micro-structures on operational performance; however we will go on to show how the Hartman-Schijve equation can be used to allow for microstructure threshold effects on the growth of both long and small cracks.

\subsection{On the relationship between small and long cracks}

Before further addressing the effect of microstructure on the growth of both long and small cracks it is first necessary to discuss the relationship between the growth of long and small cracks. It has been shown that the Hartman-Schijve equation can often be used to accurately compute the growth of both small and large cracks, under both constant amplitude and variable amplitude load spectra. This has been done for both aerospace aluminium alloys and aerospace steels subject to operational flight spectra as well as for rail bridge steels $[1,12,23$, 25, 27-29, 39-42, 55, 56]. Examples include: (i) the growth of small cracks (until failure) in the 1969 F-111 D6ac wing test [12, 41], which was tested under a representative flight load spectra; (ii) the growth of both small and long cracks in 7075-T6 under measured maritime patrol aircraft (P3C Orion) flight load spectra [23, 27, 39, 41, 55]; (iii) small cracks (until failure) in 7050-T7451, tested under a civil aircraft flight load spectrum (MiniTWIST) [27, 42]; (iv) small cracks (until failure) in 7050-T7451 tested under a measured F/A-18 flight load spectrum $[12,23,40]$. Here it should be noted that the maritime patrol aircraft flight load spectra are fundamentally different to that associated with combat aircraft. It was developed from the fleet operational usage data collected between 1991 and 1997. One block consists of $1,264,912$ cycles, corresponding to 15,000 flight hours which represents the nominal design life of the aircraft. In contrast the block loads used in the F/A-18 spectra correspond to approximately 250 flight hours. These various studies show how the $d a / d N$ versus $\Delta K$ 
relationship associated with long crack growth can be used to determine that relationship for (lead) small cracks and how this (small crack) $d a / d N$ versus $\Delta K$ curve can then be used to accurately compute the growth of small cracks under a range of different operational flight load spectra. This involves first determining the small crack $d a / d N$ versus $\Delta K$ curve from the Hartman-Schijve representation of the long crack $d a / d N$ versus $\Delta K$ curve and then setting the Hartman-Schijve equation threshold term, $\Delta K_{\text {thr }}$, to a small or zero value, typically in the range 0.0 to $0.5 \mathrm{MPa} V_{\mathrm{m}}[12,28]$.

At this stage it should be noted $[12,23]$ that the small crack $d a / d N$ versus $\Delta K$ relationship associated with lead cracks exhibits little if any $R$ ratio dependency. This behaviour can be seen in Fig. 4, which presents the 7050-T7451 small crack curves for $R=$ $-0.3,0.2,0.5$ and 0.7 . The suitability of the Hartman-Schijve to represent $R$ ratio independent small crack growth to failure is shown in [41] and in Fig. 5, for the case of a full scale F/A-18 centre barrel test under a representative flight load.

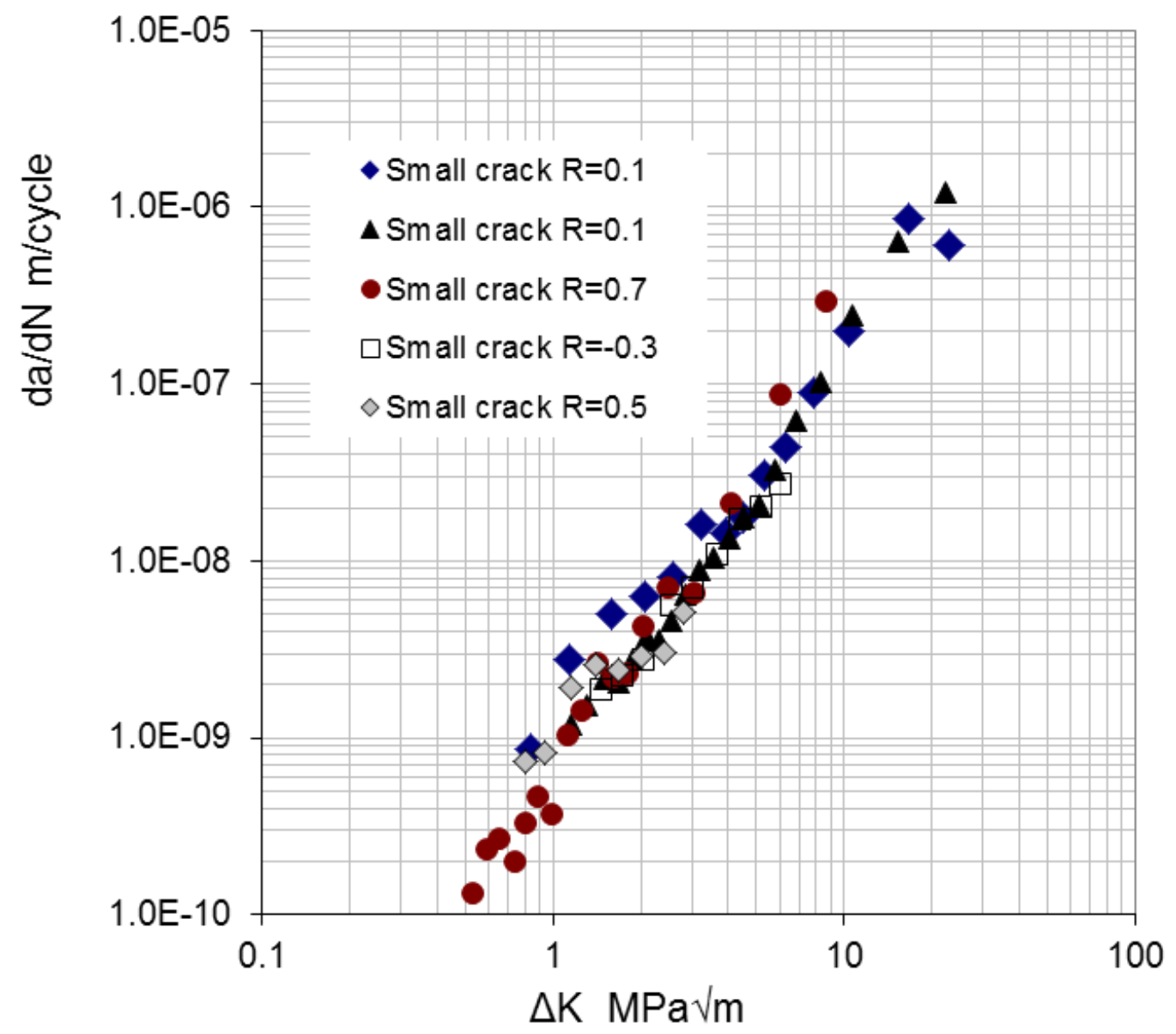

Fig. 4. Small crack growth curves for 7050-T7451 for a range of $R$ ratios, from [56]. 


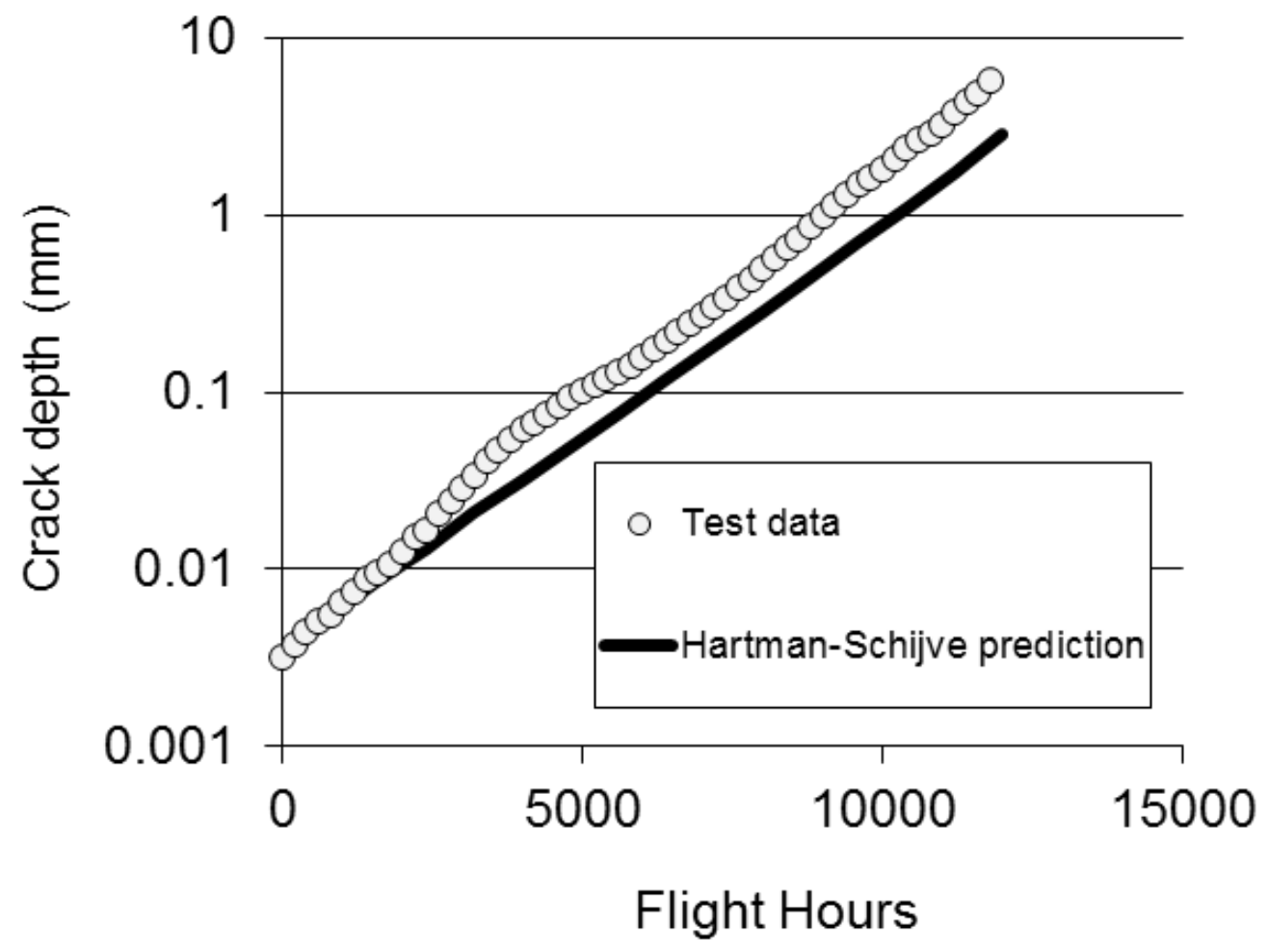

Fig. 5. Measured and predicted crack growth histories in an F/A-18 centre barrel test, from [40].

Other examples of this approach are given in [27, 39-42]. In these studies, the long crack $d a / d N$ versus $\Delta K$ representation for 7075-T6 was first determined using the NASGRO materials database. It was then shown that when using this representation the predicted and measured long crack growth histories, under two different flight load spectra, were in excellent agreement [55]. This representation was then used to predict the growth of small cracks in a specimen with a complex geometry [27]. This geometry was developed as part of the P3C Orion service life assessment program (SLAP) and consisted of a large panel with three intersecting holes, and became known as the "rabbit ear" specimen [27]. It was then shown $[39,43]$ that this formulation accurately predicted the growth to failure of small cracks from a fastener hole in a specimen cut from a P3C Orion wing plank, where the fastener hole contained an inter-granular cracking, and had two co-located satellite holes. These specimens were tested under a representative P3C flight load spectra and the agreement between the measured and computed crack growth histories is highlighted in [39].

These various examples demonstrate that the small crack $d a / d N$ versus $\Delta K$ equation determined by the procedure outlined above can be used to reasonably accurately compute crack growth from small cracks (until failure) in a range of geometries tested a range of 
operational load spectra, as well as under constant amplitude loading. We also see that this approach can be used to accurately compute the growth of small cracks in bridge steels [1].

\subsection{Computing the growth of small cracks with different microstructures}

To illustrate that the growth of small cracks with different microstructures can be computed as outlined above let us consider the $R=0.1$ small and long crack growth curves for the engine material Astroloy [9]. The small and long crack $d a / d N$ versus $\Delta K$ curves for both fine and coarse grained materials are shown in Fig. 6, where we see that the long crack fine and coarse grained differ. Figure 6 also presents the associated small and long crack curves computed using the Hartman-Schijve variant of the NASGRO equation:

$$
\frac{d a}{d N}=1.2 \times 10^{-11} \frac{\left(\Delta K-\Delta K_{\mathrm{thr}}\right)^{2}}{1-\frac{K_{\max }}{A}}
$$

A value of $A=70 \mathrm{MPa} V_{\mathrm{m}}$ was used in this analysis. This value was taken from the NASGRO materials database. As per the fatigue test standard ASTM E647-13a and [1, 12, 28] we again set the threshold term $\Delta K_{\mathrm{thr}}=0$ for the small crack tests. The constant $D=$ $1.2 \times 10^{-11}$ in equation (4) was then obtained by fitting equation (4) to the small crack data. Equation (4) was then used to predict the long crack data.

As indicated in Section 2.4, a larger value of is needed to represent long crack curves. To this end a value of $\Delta K_{\mathrm{thr}}=4.6 \mathrm{MPa} V_{\mathrm{m}}$ was used for the fine grain (FG) long crack data. A value of $\Delta \mathrm{K}_{\mathrm{thr}}=10.45 \mathrm{MPa} \sqrt{\mathrm{m}}_{\mathrm{m}}$ was used for the long crack coarse grain data. Fig. 6 shows the good agreement between the various measured and computed $d a / d N$ versus $\Delta K$ curves. Here we again see that, allowing for experimental error, the different micro-structures have little effect on the crack growth curves the effects. We also see that the effect of the different micro-structures on the $d a / d N$ versus $\Delta K$ curves can be captured by allowing for the way in which the fatigue threshold evolves with crack length. As previously, the values of the long crack threshold term $\Delta \mathrm{K}_{\text {thr }}$ were chosen based on the data at a crack growth rate of $d a / d N=$ $10^{-10} \mathrm{~m} /$ cycle. An interesting feature about Fig. 6 is that, allowing for experimental error, for the small crack tests, the $d a / d N$ versus $\Delta K$ curves for the coarse grain and the fine grain microstructures are essentially identical. This observation led [9] to the conclusion that the crack growth rate associated with these small cracks was not sensitive to the micro-structure. 


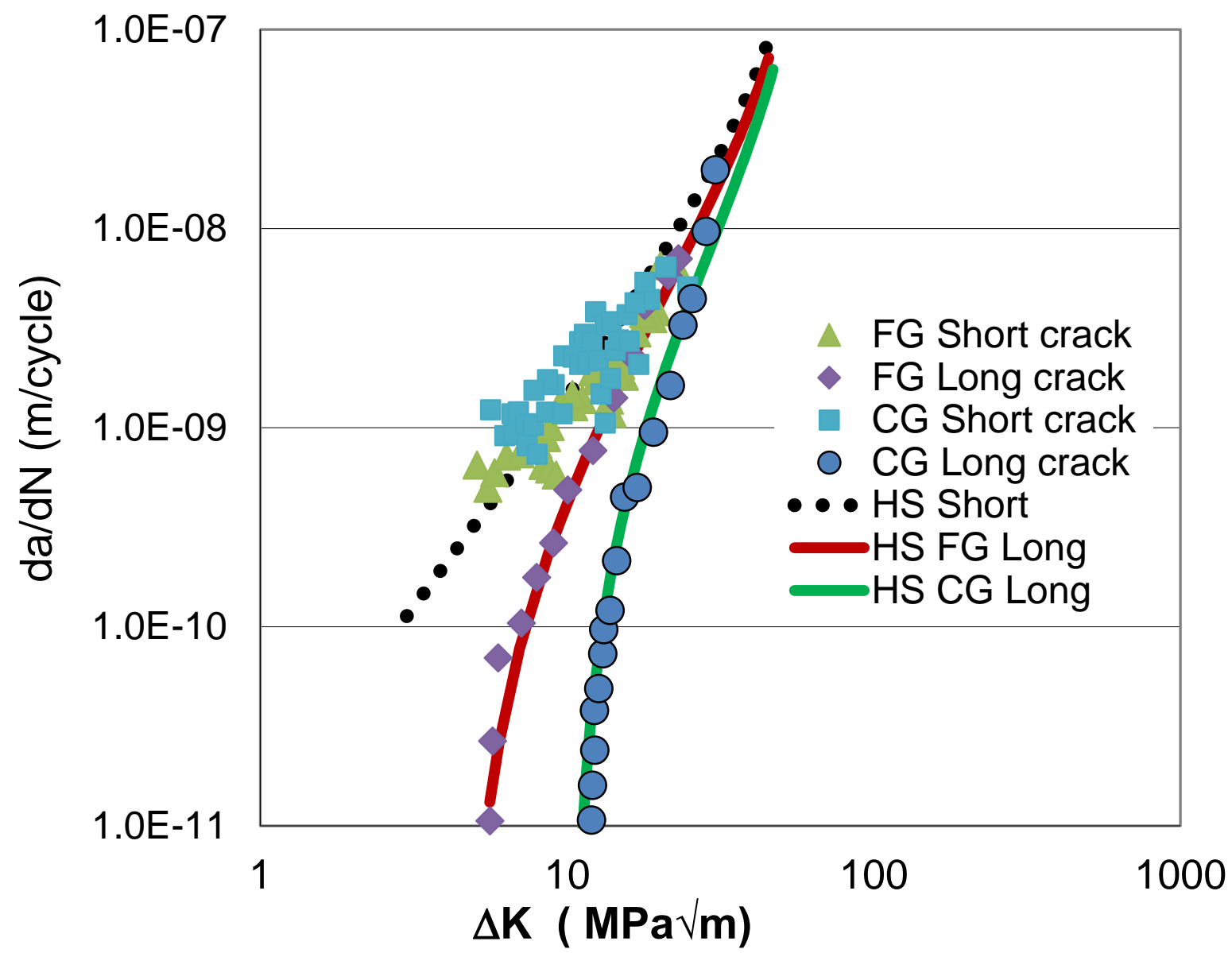

Fig. 6. Measured and computed long and short crack curves for Astoloy, data from [9]

Next consider the $R=0.1$ small and long crack growth for the engine material Ti-17 [58]. The small crack $d a / d N$ versus $\Delta K$ curve presented in [58] is shown in Fig. 7. This curve can also be represented using the Hartman-Schijve variant of the NASGRO equation:

$$
\frac{\mathrm{da}}{\mathrm{dN}}=4.0 \times 10^{-10} \frac{\left(\Delta \mathrm{K}-\Delta \mathrm{K}_{\mathrm{thr}}\right)^{2}}{1-\frac{K_{\max }}{A}}
$$

with $\Delta K_{\text {thr }}=0.5 \mathrm{MPa} \vee_{\mathrm{m}}$, and the toughness value, $A=75 \mathrm{MPa} \sqrt{\mathrm{m}}_{\mathrm{m}}$, is taken from [57].

The computed, using equation (5), long crack $R=0.1$ curve, using $\Delta K_{\mathrm{thr}}=4.7 \mathrm{MPa} V_{\mathrm{m}}$, and the long crack $R=0.7 \mathrm{da} / \mathrm{dN}$ versus $\Delta K$ curve using with $\Delta K_{\mathrm{thr}}=1.0 \mathrm{MPa} \sqrt{\mathrm{m}}$, are shown in Fig. 7. Here, we again see good agreement between the various measured and computed $d a / d N$ versus $\Delta K$ curves. In this instance, since there was no data associated with a crack growth rate of $d a / d N=10^{-10} \mathrm{~m} /$ cycle, the value of the threshold term $\Delta K_{\text {thr }}$ was chosen so 
as to ensure that the measured and computed curves coincided at a crack growth rate of $d a / d N=3.5 \times 10^{-10} \mathrm{~m} /$ cycle, which was the lowest crack growth rate in the data set.

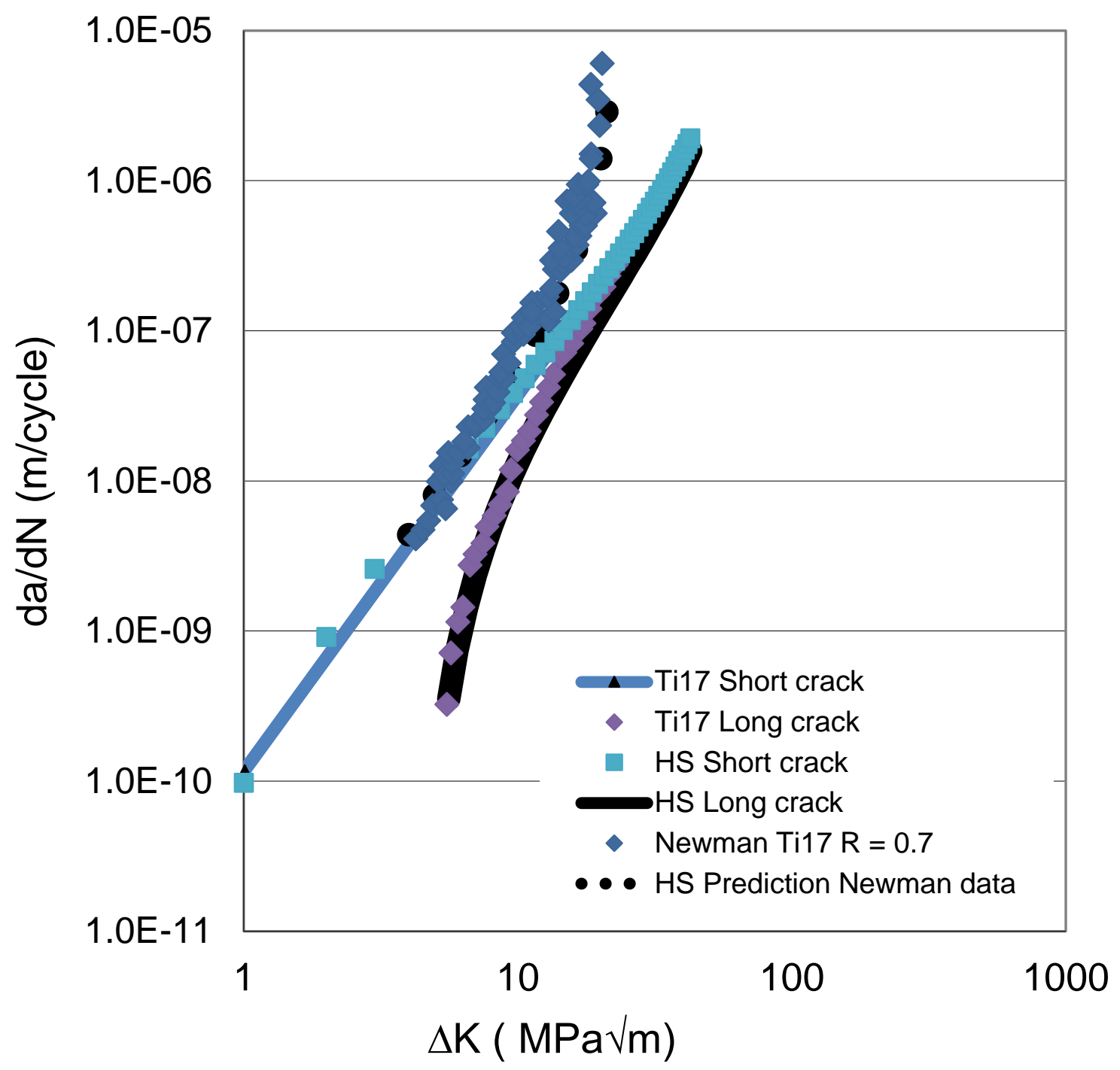

Fig. 7. Measured and computed long and small crack curves for Ti17, data from [57, 58].

Let us next examine the paper by Lados, Apelian, Paris and Donald [13], which addressed the effect of micro-structure and chemical composition on the growth of both long and short cracks in three Al-Si-Mg alloys, where the cracks were grown from an artificial $0.5 \mathrm{~mm}$ deep triangular starter notch, and hence are termed short rather than small cracks. In these alloys, the $\mathrm{Si}$ content was 1, 7, and 13\%, and the $\mathrm{Mg}$ was at a fixed level of $0.45 \%$. Although changes in the $\mathrm{Si}$ content gave rise to significant changes in the fracture toughness, no specific values for the associated toughness's were given. The effect of the different Si content, i.e. different compositions, on the short crack $d a / d N$ versus $\Delta K$ curves is shown in Fig. 8. 


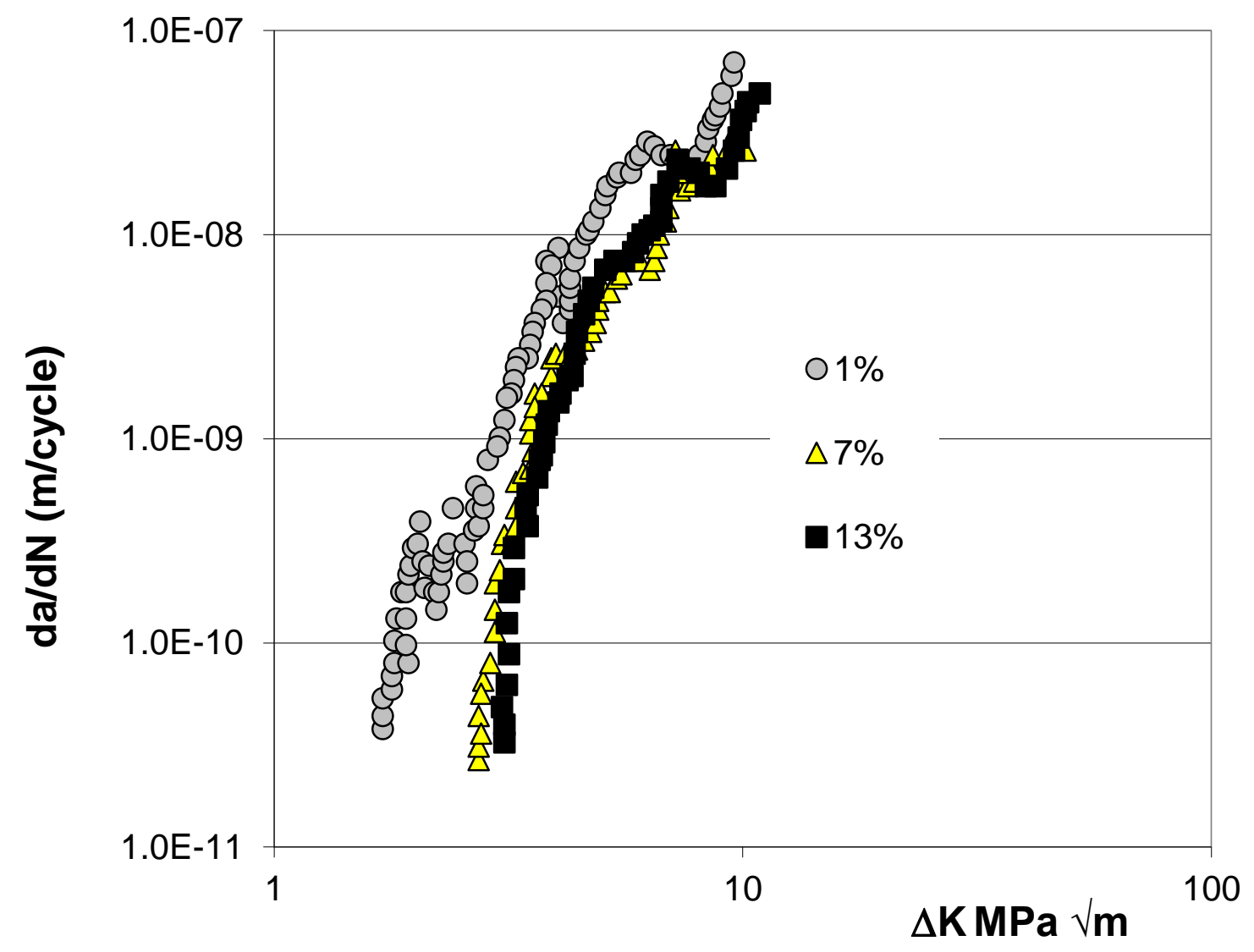

Fig. 8. Effect of different Si content, data from [13].

Let us next investigate whether this short crack behaviour can be represented by the HartmanSchijve variant of the NASGRO equation. Recalling the form of the Hartman-Schijve equation, see equation (1), the constants in the small crack representation for these various $\mathrm{Al}-\mathrm{Si}-\mathrm{Mg}$ alloys can be determined by plotting

$$
\frac{d a}{d N} \text { against } \frac{\Delta K-\Delta K_{\mathrm{thr}}}{\sqrt{1-\frac{K_{\max }}{A}}} .
$$

Using the values given in Table 1 and taking the values of the fracture toughness from Fig. $2 \mathrm{~b}$ in [13] it appears that, allowing for experimental error, the short crack growth curves in these three different microstructures can all be approximated by a single equation, i.e. equation (1), with slightly different values for the threshold term $\Delta K_{\text {thr }}$, see Fig. 9. The values of the constants used in this representation are given in Table 1. Here it should be noted that these are short cracks that have been grown from an artificial $0.5 \mathrm{~mm}$ triangular notch, and as such 
have larger values of $\Delta K_{\text {thr }}$ than cracks that arise naturally in operational aircraft and have initial lengths of $0.05 \mathrm{~mm}$ or less.

Table 1. Short crack $\Delta K_{\text {thr }}$ values for different Si content

\begin{tabular}{ccccc}
\hline Si content $(\%)$ & $A(\mathrm{MPa} \sqrt{\mathrm{m}})$ & $\Delta K_{\text {thr }}(\mathrm{MPa} \sqrt{\mathrm{m}})$ & $p$ & $D$ \\
\hline 1 & 18 & 1.51 & 2 & $7.6 \times 10^{-10}$ \\
7 & 30 & 2.55 & 2 & $7.6 \times 10^{-10}$ \\
13 & 35 & 2.85 & 2 & $7.6 \times 10^{-10}$ \\
\hline
\end{tabular}

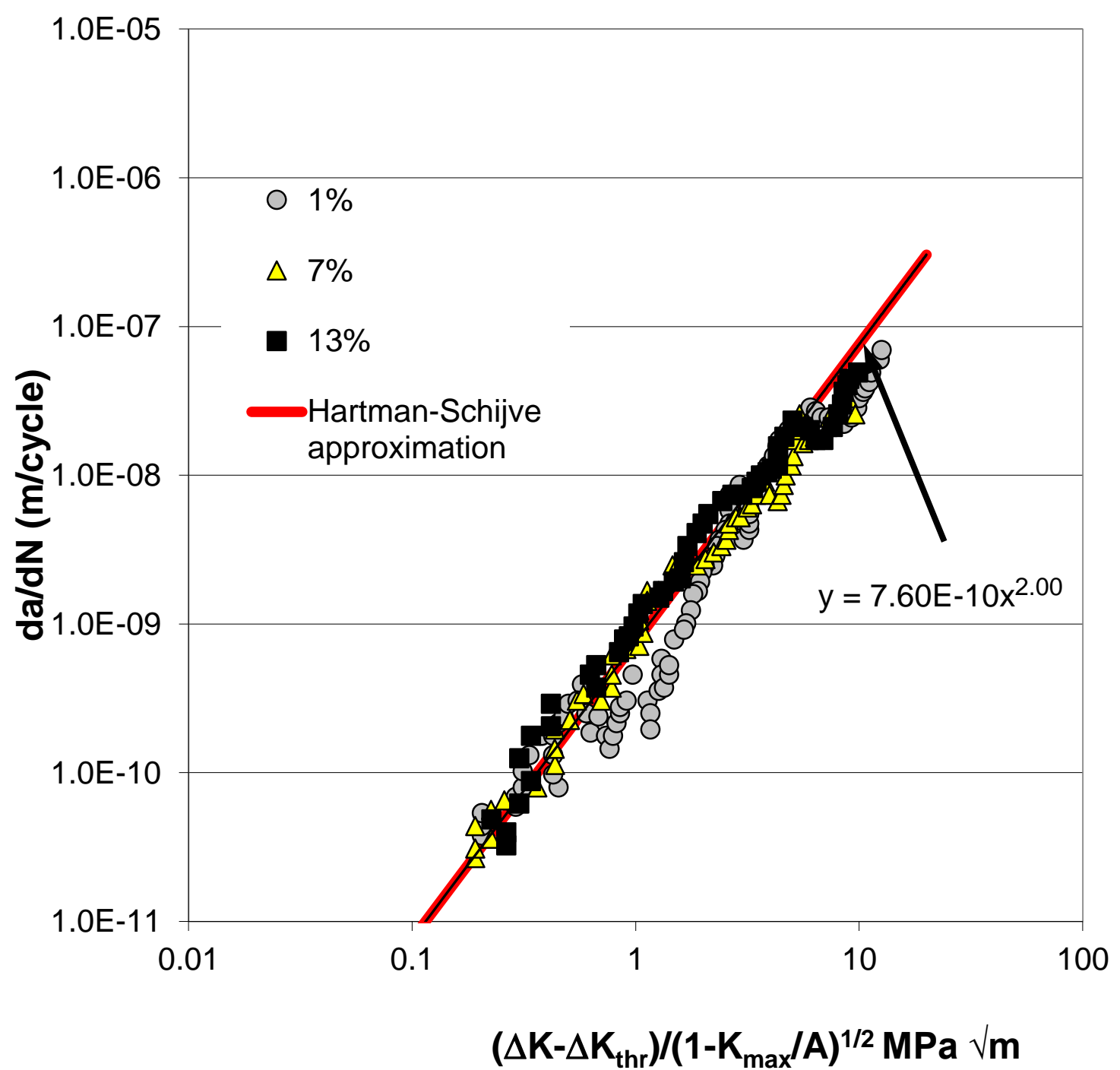

Fig. 9. Hartman-Schijve representation, data from [13].

Having thus determined the constants in the Hartman-Schijve representation for these three different compositions let us next examine whether, as found in the previous studies, the various long crack $d a / d N$ versus $\Delta K$ curves can be predicted by changing the value of the threshold term, $\Delta K_{\text {thr }}$. To this end, let us first consider the $K_{\max }=11 \mathrm{MPa} V_{\mathrm{m}}$ tests presented 
in [13]. The resulting $d a / d N$ versus $\Delta K$ curves are given in Fig. 10, along with the curves computed using equation (1) with the values of $A, D$ and $p$, as given in Table 1 , and with the values of $\Delta K_{\text {thr }}$ given in Table 2. Fig. 10 shows that, allowing for experimental error, the measured and computed curves are in reasonably good agreement. As previously, the values of the long crack threshold values $\Delta K_{\text {thr }}$ were chosen so as to ensure that the measured and computed curves essentially coincided at a crack growth rate of $d a / d N=10^{-10} \mathrm{~m} /$ cycle.

Table 2. Long crack $\Delta K_{\text {thr }}$ values for $K_{\max }$ tests on different Si contents

\begin{tabular}{cc}
\hline Si content $(\%)$ & $\Delta K_{\text {thr }}(\mathrm{MPa} \sqrt{\mathrm{m}})$ \\
\hline 1 & 1.20 \\
7 & 1.18 \\
13 & 1.28 \\
\hline
\end{tabular}

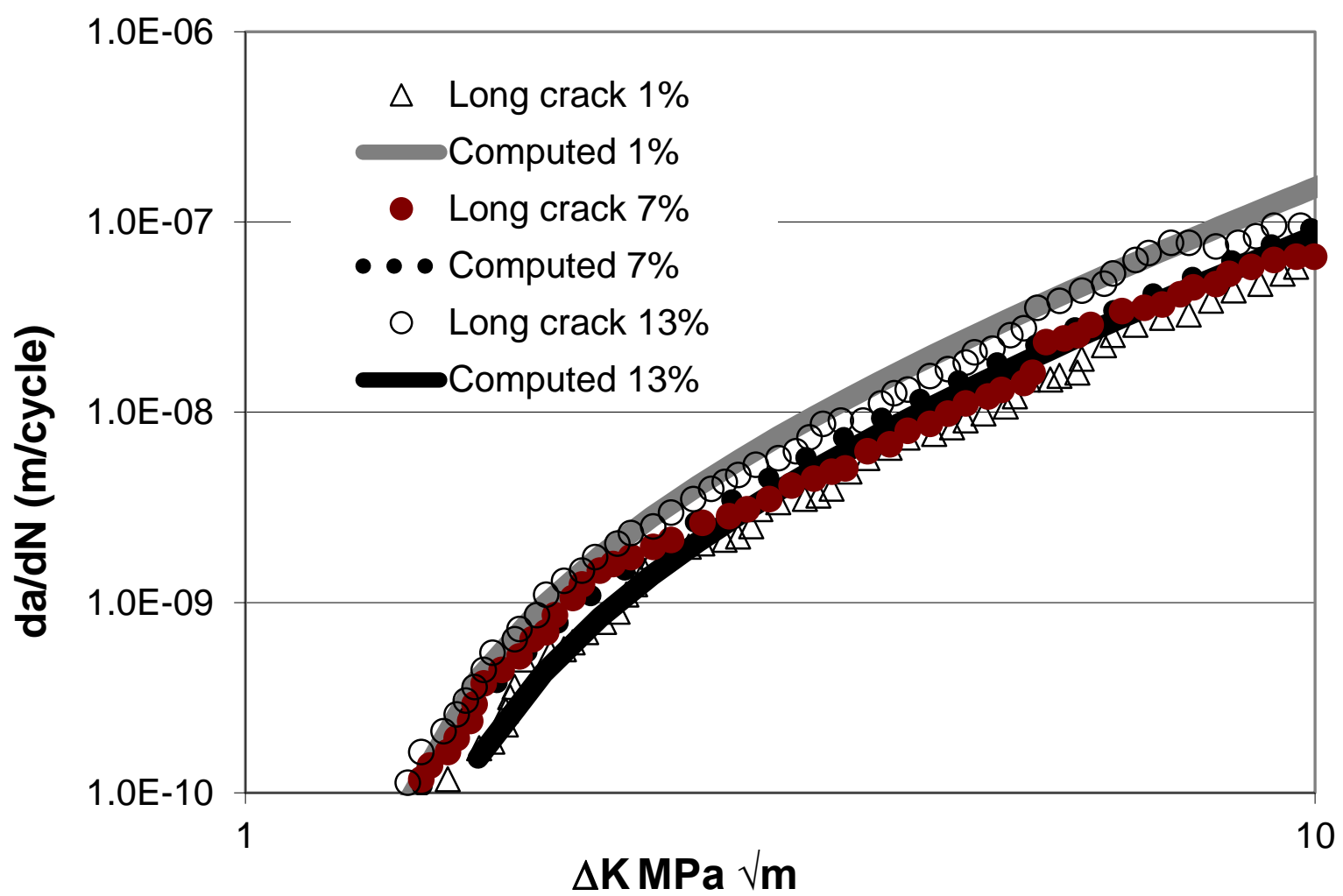

Fig. 10. Measured and computed curves for the $K_{\max }$ tests, data from [13].

Continuing this study, the measured resulting $d a / d N$ versus $\Delta K$ long crack curves for the $R=0.1$ tests are given in Fig. 11, along with the curves computed using equation (1), again with the values of $A, D$ and $p$ as given in Table 1, and this time with the values of $\Delta K_{\text {thr }}$ given in Table 3. In this instance, since the $7 \%$ and $13 \%$ curves are so similar, only the computed $13 \%$ curve has been plotted. Fig. 11 reveals that, as is the case for the short crack and the 
$K_{\text {max }}$ tests, allowing for experimental error, the measured and computed long curves are in reasonably good agreement. That is to say that equation (1) is reasonably able to represent the effect of changes in the micro-structure on the growth of both short (cracks that were grown form a $0.5 \mathrm{~mm}$ deep artificial notch) and long cracks.

Table 3. Long crack values $K_{\text {thr }}$ for $R=0.1$ tests on specimens with different $\mathrm{Si}$ contents

\begin{tabular}{cc}
\hline Si content $(\%)$ & $\Delta K_{\text {thr }}(\mathrm{MPa} \sqrt{ } \mathrm{m})$ \\
\hline 1 & 3.87 \\
7 & 4.40 \\
13 & 4.75 \\
\hline
\end{tabular}

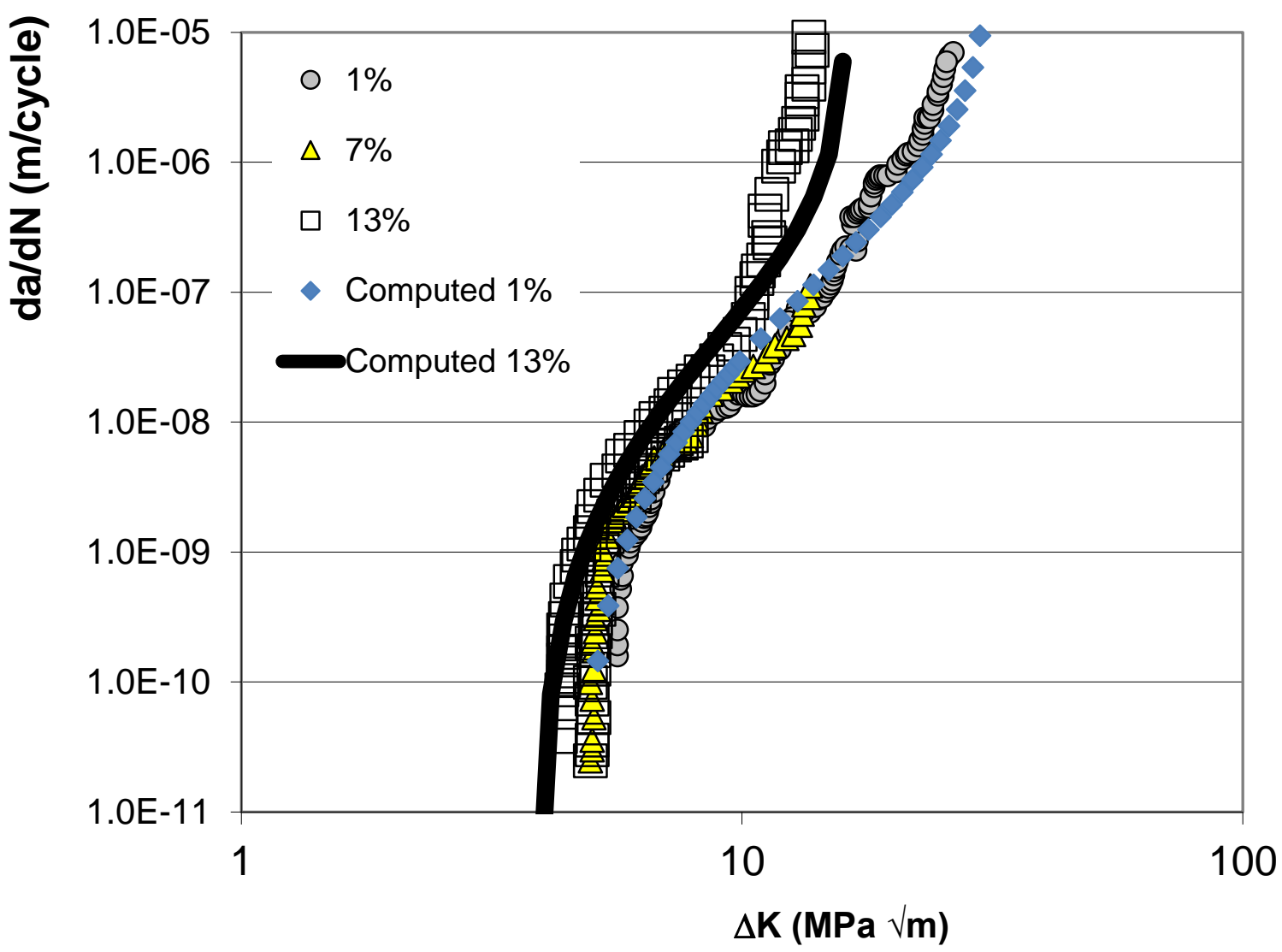

Fig. 11. Measured and computed long crack growth curves for the $R=0.1$ tests, data from [13].

This example, when taken together with the results presented above, suggests that the effect of the different micro-structures and different compositions on crack growth can be captured reasonably well by allowing for changes in the threshold term. Equation (1) thus suggests that the effect of microstructure on crack growth will generally be less significant for small lead cracks for which the fatigue threshold is often very small, see Appendix X3 of the ASTM fatigue test standard E647-13a and [12, 26, 28]. An example of this phenomenon 
is seen in Fig. 10, where it is shown that although the fine grain (FG) and the coarse grain (CG) Astroloy microstructures had quite different long crack $d a / d N$ versus $\Delta K$ curves the corresponding small crack curves were very similar.

This conclusion is also consistent with the findings presented in [38] where it is stated:

“... although up to 4 orders of magnitude faster than long cracks, small crack growth rates in 2090, 2091 and 8091 remain comparable with behaviour in traditional alloys, such as 2124-T351 and 7150-T751.”

Venkatraman and Ritchie [38] also suggested that the origin of micro-structural effects on fatigue crack propagation behaviour in aluminium alloys results primarily from shielding mechanisms; however, since as explained in ASTM E647-13a and [12, 59] for small cracks crack tip shielding is greatly reduced, we see that this conclusion is similar to that enunciated above, that the effect of micro-structure on the growth of lead cracks should generally be less significant for small cracks.

\section{ATOMISTIC MODELS}

Having seen that the growth of small lead cracks often conforms to a Paris like crack growth equation let us next examine the results obtained via atomistic simulation of crack growth. In this context it should be noted that the review paper by Horstemeyer et al [60] concluded that atomistic modelling often results in a Paris like crack growth curve. With this in mind Fig. 12 presents the atomistic model $d a / d N$ versus $\Delta K$ curves and the corresponding long crack curves for copper with two grain sizes, viz: 12 and 120 microns, presented in [61] together with plots of the intrinsic crack growth curve $d a / d N$ versus $\Delta K_{\text {eff }}=\left(\Delta K-\Delta K_{\text {thr }}\right)$ obtained, as per section 2, from the NASGRO representation of the long crack curve with the threshold term $\Delta K_{\text {thr }}$ set to 0.0 . (Here it should be noted that [61] referred to the 120 microns $d a / d N$ versus $\Delta K_{\text {eff }}$ curve as long 120 microns and as such this notation is used in Fig. 12.) In this instance since the value $\mathrm{A}$ was unknown and since the $\Delta K$ data was limited to values beneath $15 \mathrm{MPa} \sqrt{ } \mathrm{m}$ the term on the denominator has been neglected, i.e. as a first

approximation we have ignored the term $\sqrt{1-K_{\max } / A}$. Here we see that, allowing for numerical error, the "nano scale" curves determined via the atomistic analysis exhibit a Paris 
like relationship and that, to a first approximation, the atomistic curves and the curves computed using equation (1) with the threshold set to a small value are in reasonably good agreement.

Paris like curves resulting from the atomistic modelling of the crack growth process are also given in $[62,63]$. Unfortunately, many of these studies do not contain the associated long crack experimental data needed to perform the analysis/assessment shown in Fig. 13. A feature of Fig. 12 is that it resembles the shape of the $d a / d N$ versus $\Delta K$ curves shown in Figs. 3 and 11, and that the crack growth curves associated with the nano scale (atomistic) analysis resemble the small crack curves shown in Fig. 4.

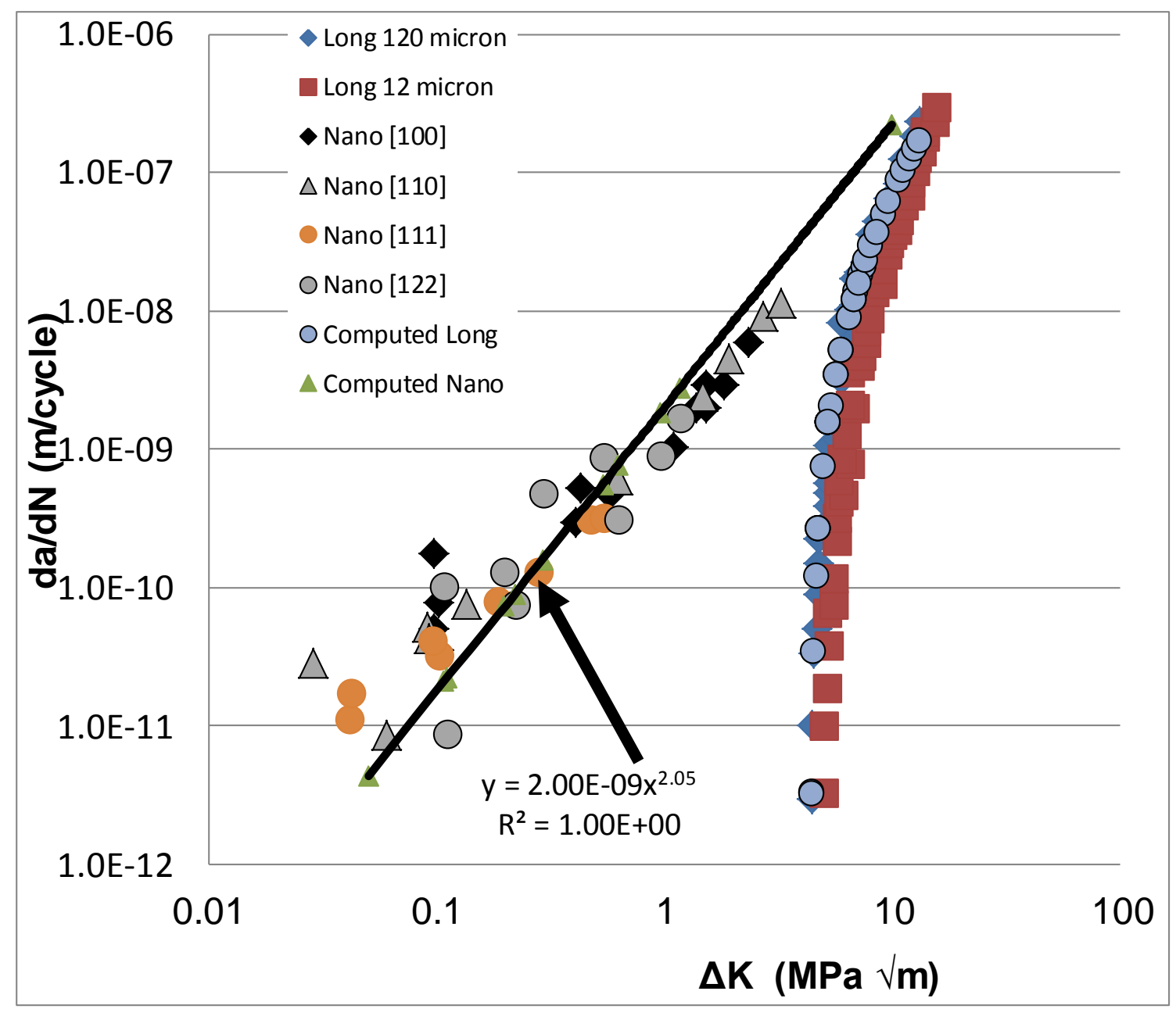

Fig. 12. The atomistic and long crack growth data in [60] replotted.

The paper by Chowdhury, Sehitoglu, Rateick and Maier of [64] is interesting since it addresses the topic of the role of nanoscale coherent twin boundaries on fatigue crack growth. 
The atomistic simulations led [64] to paper conclude that fatigue crack growth is governed by the dislocation glide resistance and the irreversibility of crack tip displacement, both of which are influenced by the presence of nanoscale coherent twin boundaries. Simulation results were presented [64] for a Ni-Co alloy with both different twin thicknesses (t) and different twin spacings $(d)$. The simulation results obtained for $d=8 \mathrm{~nm}$ are shown in Fig. 13 where we have plotted the $d a / d N$ against $\left(\Delta K-\Delta K_{\text {thr }}\right) / \sqrt{1-K_{\max } / A}$ using the value $A=180$ $\mathrm{MPa} V_{\mathrm{m}}$ which is a typical value for this alloy. In this case we see that different twin thicknesses result in the NASGRO like equation (1) with the different twin thicknesses (t) simulations having similar value for $p$. The values of the threshold term $\Delta K_{\text {thr }}$ used in Fig. 13 are given in Table 4.

Table 4. Threshold values for $d=80 \mathrm{~nm}$

\begin{tabular}{cc}
\hline$t(\mathrm{~nm})$ & $\Delta K_{\text {thr }}(\mathrm{MPa} \sqrt{\mathrm{m}})$ \\
\hline 0 & 2.6 \\
10 & 3.4 \\
5 & 4.4 \\
2 & 5.5 \\
\hline
\end{tabular}

The corresponding data, presented in [64], for the case of a fixed $t(=80 \mathrm{~nm})$ and varying twin spacings $(d)$ is shown in Fig. 13. Here we again see that the simulated crack growth curves conform to equation (1) albeit with different thresholds. The values of the threshold term $\Delta K_{\text {thr }}$ used in Fig. 14 are given in Table 5.

Table 5. Threshold values for $t=80 \mathrm{~nm}$

\begin{tabular}{cc}
\hline$d(\mathrm{~nm})$ & $\Delta K_{\text {thr }}(\mathrm{MPa} \sqrt{\mathrm{m}})$ \\
\hline No twin & 2.5 \\
10 & 4.3 \\
5 & 5.7 \\
2 & 7.3 \\
\hline
\end{tabular}




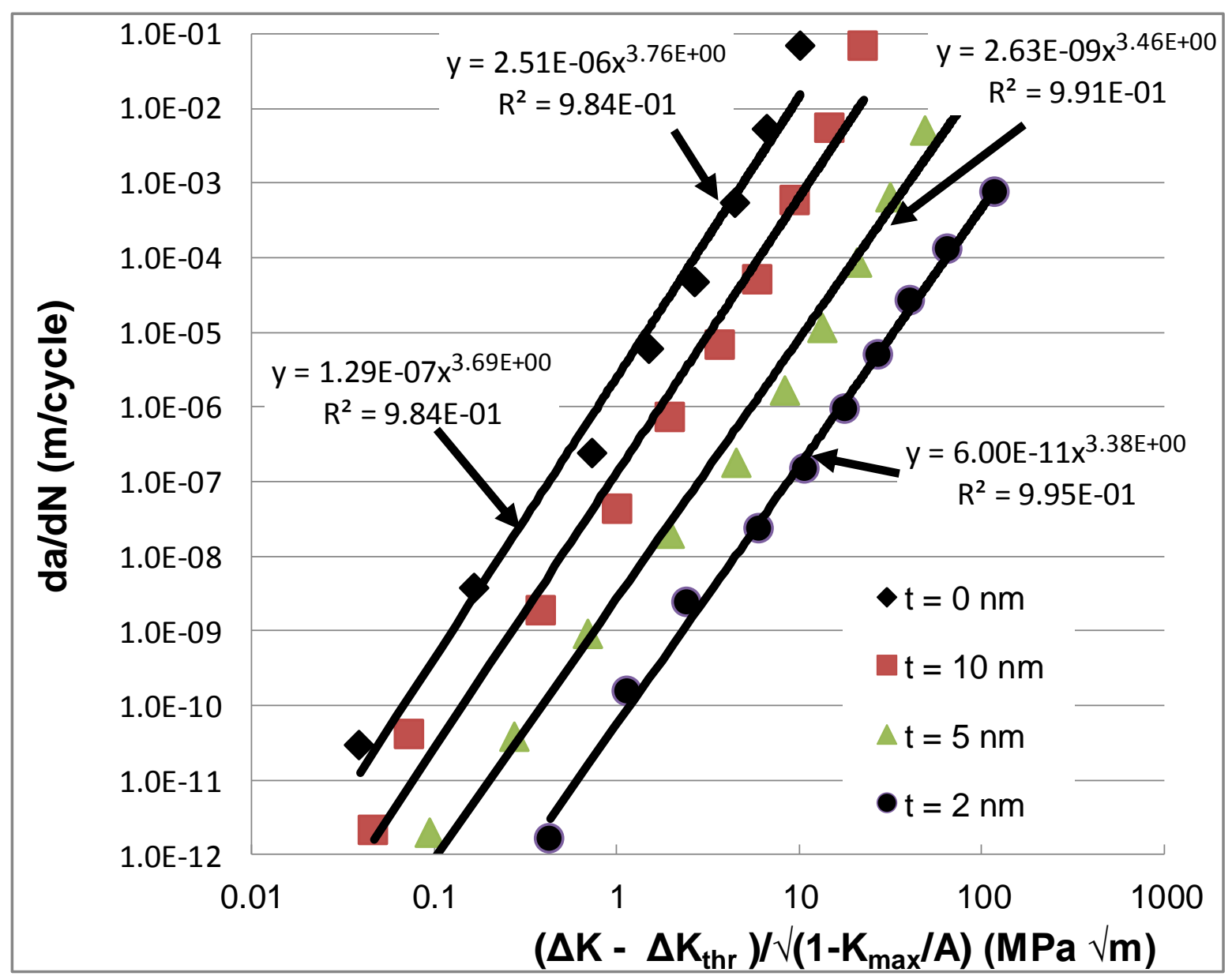

Fig. 13. The atomistic crack growth data presented in [64] for $d=80 \mathrm{~nm}$ replotted 


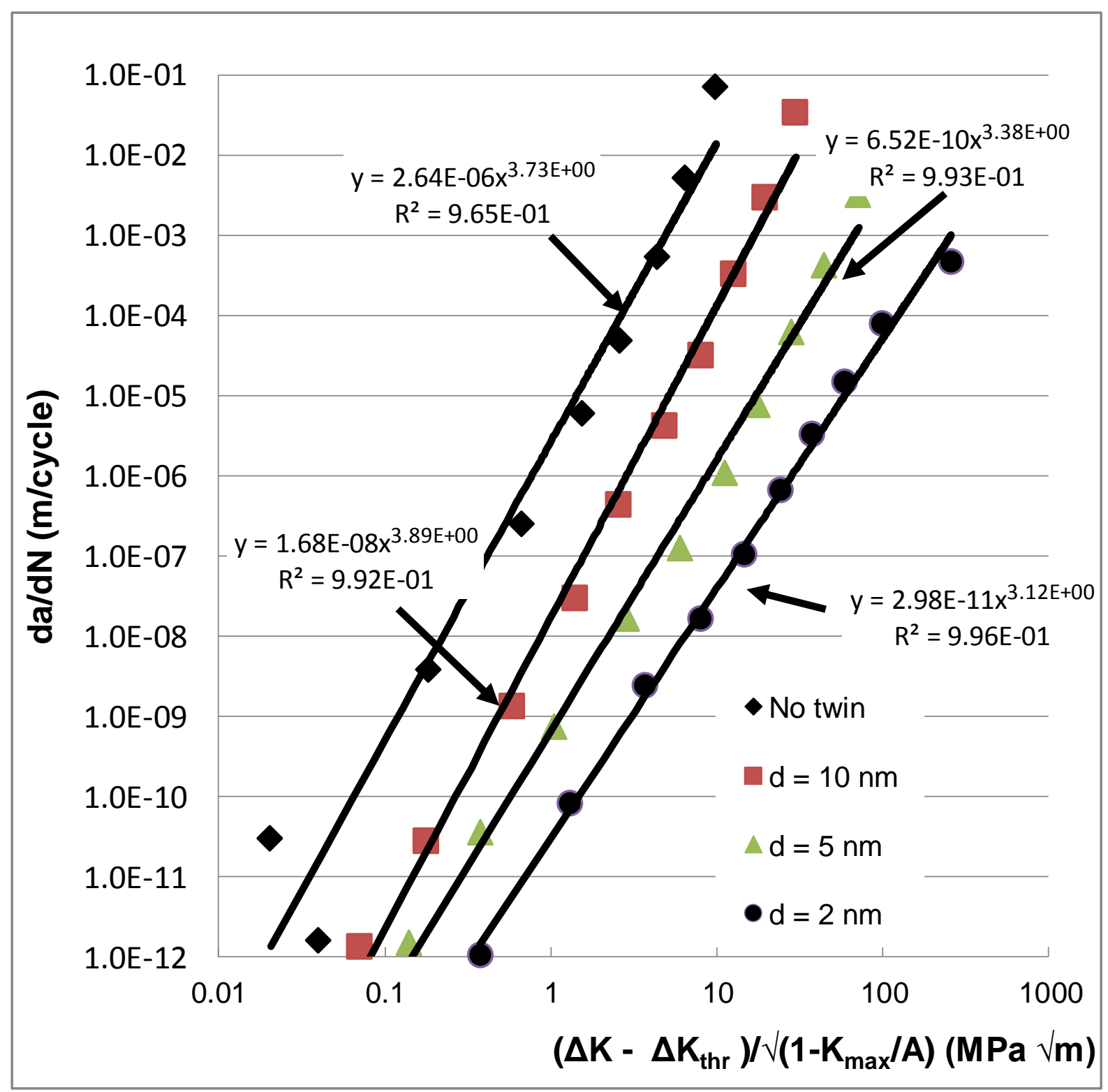

Fig. 14. The atomistic crack growth data presented in [64] for $t=80 \mathrm{~nm}$ replotted.

These various studies support the finding given in [60] that atomistic modelling of the fatigue crack growth process often yields a simple Paris like behaviour. We also see that, for the cases considered, atomistic modelling yields $d a / d N$ versus $\Delta K$ curves that are consistent with the Hartman-Schijve variant of the NASGRO crack growth equation discussed in Section 2 . 


\section{COMPARING THE GROWTH OF SMALL CRACKS IN A RANGE OF MATERIALS WITH DIFFERENT MICROSTRUCTURES}

As previously discussed small naturally occurring cracks generally exhibit little $R$ ratio dependence, see Fig. 4, and the associated small crack $d a / d N$ versus $\Delta K$ curve can often be approximated by a simple "Paris like" crack growth equation. We have also seen that different microstructures need not significantly affect small crack growth. To further illustrate this, Fig. 15 plots the small crack growth $d a / d N$ versus $\Delta K$ curves for: i) A $350 \mathrm{MPa}$ grade locomotive rail steel [1], which was tested at a range of $R$ ratios; ii) The aerospace quality titanium alloys Ti-17 [58] and Ti-6246 (Ti-6Al-2Sn-4Zr-6Mo) [65], which were tested at a range of $R$ ratios. (In [58], the Ti-17 $d a / d N$ versus $\Delta K$ curves were $R$ ratio independent, so only a single curve is shown). A description of the specimen identifiers given in Fig. 15 for the locomotive steel tests is given in Table 6.

Table 6: Test envelope, from [1], for small cracks growth in the locomotive steel

\begin{tabular}{cccccccccc}
\hline $\begin{array}{c}\text { Specimen } \\
\text { Number }\end{array}$ & $\begin{array}{c}\text { Width } \\
(\mathrm{mm})\end{array}$ & $\begin{array}{c}\text { Thickness } \\
(\mathrm{mm})\end{array}$ & $\begin{array}{c}\text { Notch } \\
(\mathrm{mm})\end{array}$ & $\begin{array}{c}\text { Area } \\
\left(\mathrm{mm}^{2}\right)\end{array}$ & $\mathrm{R}$ & $\begin{array}{c}\sigma_{\max } \\
(\mathrm{MPa})\end{array}$ & $\begin{array}{c}\sigma_{\min } \\
(\mathrm{MPa})\end{array}$ & $\begin{array}{c}\Delta \sigma \\
(\mathrm{MPa})\end{array}$ & $\begin{array}{c}\sigma_{\text {mean }} \\
(\mathrm{MPa})\end{array}$ \\
\hline L1 & 50.12 & 5.16 & 1.0 & 253.46 & 0.14 & 330.0 & 46.2 & 283.8 & 188.1 \\
L2 & 50.15 & 5.41 & 1.0 & 265.90 & 0.50 & 330.0 & 165.0 & 165.0 & 247.5 \\
L3 & 50.04 & 5.32 & 1.0 & 260.89 & 0.50 & 330.0 & 165.0 & 165.0 & 247.5 \\
L4 & 49.94 & 5.38 & 1.0 & 263.30 & -1.0 & 240.0 & -240.0 & 240.0 & 0.0 \\
L5 & 50.00 & 5.64 & 1.0 & 276.36 & 0.14 & 330.0 & 46.2 & 283.8 & 188.1 \\
L6 & 49.95 & 5.61 & 1.0 & 274.61 & 0.50 & 330.0 & 165.0 & 165.0 & 247.5 \\
L7 & 49.95 & 5.64 & 1.0 & 276.08 & 0.14 & 330.0 & 46.2 & 283.8 & 188.1 \\
L8 & 49.98 & 5.66 & 1.0 & 277.23 & 0.14 & 330.0 & 46.2 & 283.8 & 188.1 \\
L9 & 50.11 & 5.65 & 1.0 & 277.47 & 0.50 & 330.0 & 165.0 & 165.0 & 247.5 \\
S11 & 50.13 & 5.39 & 1.0 & 264.81 & 0.50 & 330.0 & 165.0 & 165.0 & 247.5 \\
S12 & 50.11 & 5.64 & 1.0 & 276.98 & 0.14 & 330.0 & 46.2 & 283.8 & 188.1 \\
S13 & 50.05 & 5.34 & 1.0 & 261.93 & 0.50 & 330.0 & 165.0 & 165.0 & 247.5 \\
\hline
\end{tabular}

Fig. 15 demonstrates that, despite the large differences in micro-structure, yield stress and chemical composition, the $d a / d N$ versus $\Delta K$ curves associated with this locomotive steel and the two aerospace titaniums appear, to within experimental error, to essentially follow the same curve. This represents a further confirmation of the statement presented earlier in this paper. When taken in conjunction with Figs. 4, 7, 12-14, Fig. 15 illustrates that:

a) Small crack growth is largely unaffected by the $R$ ratio, and that 
b) The small crack $d a / d N$ versus $\Delta K$ curve can be often be approximated by a simple Paris like crack growth equation $[1,12,23,26,54,58,65,66]$.

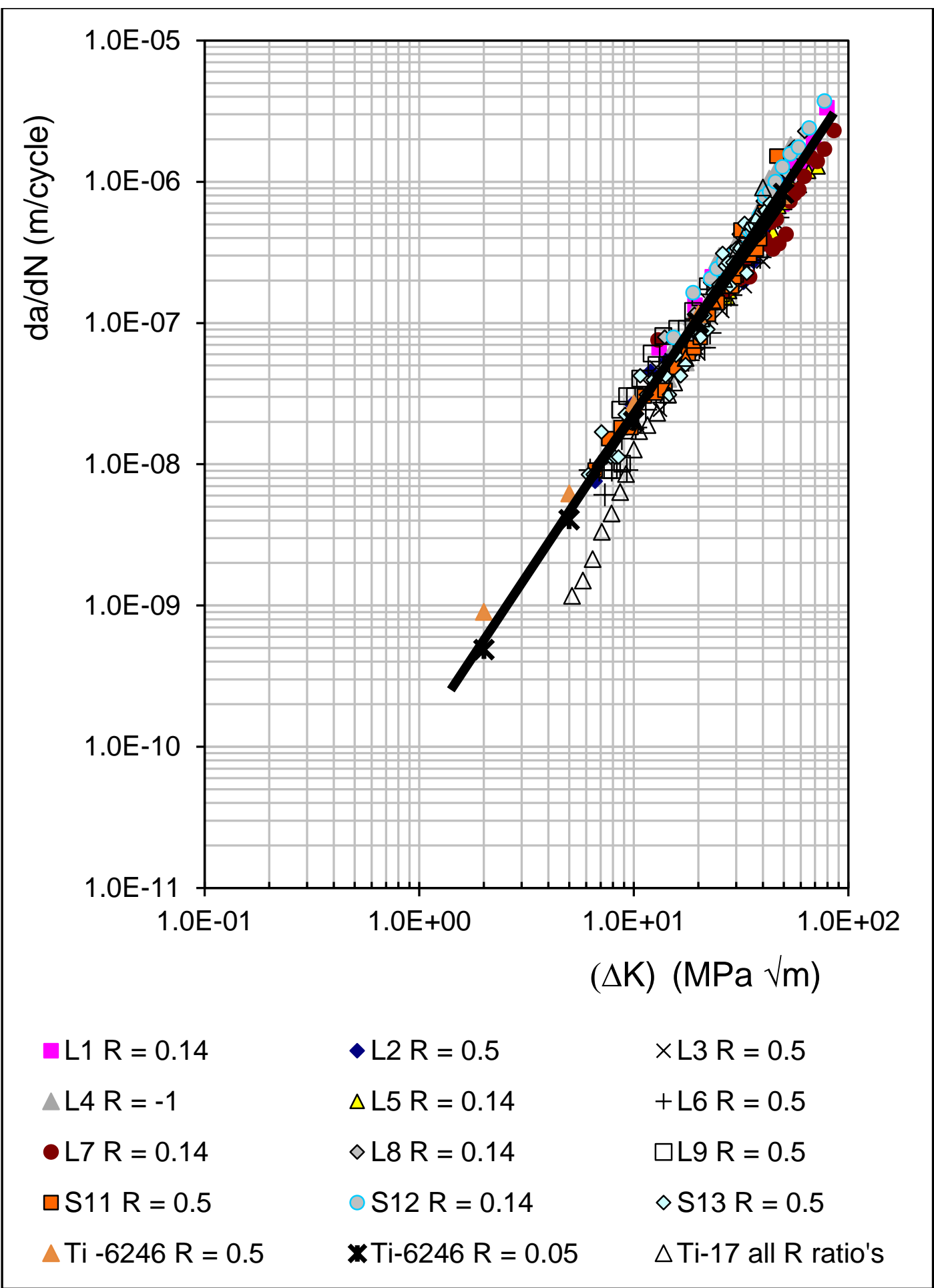

Fig. 15. Experimental small $d a / d N$ vs $\Delta K$ curves for a $350 \mathrm{MPa}$ grade locomotive rail steel [1] and the aerospace quality titanium alloys Ti-6246 [65] and Ti-17 [58]. 


\section{A NON DIMENSIONAL REPRESENTATION OF CRACK GROWTH IN OPERATIONAL AIRCRAFT}

We have seen that in the context of aircraft sustainment, the need to be able to represent the growth of cracks from small naturally occurring material discontinuities and small manufacturing defects accurately is particularly important. It is now known, that for cracks that have grown from small naturally occurring material discontinuities, the $d a / d N$ versus $\Delta K$ is not unique [27], and that the variability in the crack growth curves can often be captured approximately by allowing for changes in the threshold term $\Delta \mathrm{K}_{\text {thr }}$ in the HartmanScijve variant of the NASGRO crack growth equation [12, 27, 28]. Interestingly this is also true for the variability seen in delamination growth in composites $[67,68]$, where the terms $\Delta K$ and $K_{\max }$ are replaced by $\Delta \sqrt{G}$ and $\sqrt{G_{\max }}$ respectively, where $G$ is the energy release rate. An advantage of the Hartman-Schijve formulation is that despite the very large scatter seen in delamination growth, it enables conservative estimates to be obtained for delamination growth, as well as conservative estimates for the associated delamination fatigue threshold [68].

It has long been known that the operational life of an airframe is governed by the growth of lead cracks, i.e. the fastest cracks in the structure $[12,18,21,26,28,101]$ which invariably start to grow shortly after the aircraft is introduced into service. In this context we have seen that these small crack curves are essentially Paris curves [12, 23, 26, 28, 29, 39, 40, 54, 58, $65,66,69]$ with an exponent that is often approximately 2 , so that to a first approximation $\mathrm{da} / \mathrm{dN}$ becomes proportional to the crack length $a[12,19-21,69]$ so that the crack length history is approximately exponential. Hence, it would appear that crack growth from small sub mm cracks up to failure under a range of different flight load spectra can be reasonably accurately computed using the small crack growth equation, i.e. equation (1) with the threshold term set to a small value and a value of $p$ that is often approximately 2 .

The need to be able to accurately represent the growth of lead cracks in operational aircraft led the USAF [21] to develop a risk of failure approach that is based on the fact that crack growth in operational aircraft was essentially exponential and as such could be expressed in the form: 


$$
a=a_{0} \times e^{\omega} B
$$

where $a_{0}$ is the size of the initial material discontinuity, $\omega$ is spectrum and geometry dependent, and $B$ is the number of flight hours, or the number of load blocks in a full scale fatigue test. This finding has subsequently been independently verified [70,83]. Equation (6) has been shown to follow directly from the form of the Hartman-Schijve crack growth equation associated with small naturally occurring cracks [12]. It has subsequently been shown [12] that the Hartman-Schijve equation suggests that the crack growth history associated with lead cracks that initiate from such small material discontinuities should conform approximately to:

$$
\frac{B-B_{i}}{B_{f}-B_{i}}=1-\frac{\ln \left(a / a_{f}\right)}{\ln \left(a_{i} / a_{f}\right)}
$$

Here $B_{i}$ and $B_{f}$ and $a_{i}$ and $a_{f}$ are the start and end values of the number of the number of load blocks (or simulated flight hours) and the crack lengths respectively, see [12, 41]. This predicted behaviour has been shown [41] to hold for cracking seen in a range of aircraft under a range of operational flight load spectra. As shown in [12] the Hartman-Schijve equation also predicts that equation (7) should hold for centre notch cracks (middle tension) and surface cracks in a large panel. This prediction was validated for

a) Crack growth data presented in [71] for growth in a $6.3 \mathrm{~mm}$ thick and $610 \mathrm{~mm}$ wide centre cracked panel tests for 2324-T39, 2024-T351, 7075-T651, 7150-T651, and 2024-T3 aluminium alloys tested under a range of representative civil aircraft load spectra, which [66] termed transport spectra A, B, and C. This data was obtained as part of the Boeing 757 and the 767 materials development program;

b) Crack growth data presented by Northrop-Grumman [72] who studied crack growth in a $12.7 \mathrm{~mm}$ wide and $7.34 \mathrm{~mm}$ thick centre cracked Mil Annealed Ti-6AL-4V panel subjected to a fighter load spectrum with a peak remote stress of $710 \mathrm{MPa}$ and a similar dimension 2219-T851 panel subject to the same fighter spectrum except that the peak stress in the spectrum was $215.8 \mathrm{MPa}$; 
c) The results of a NASA study [73] into $198 \mathrm{~mm}$ by $50.8 \mathrm{~mm}$ centre cracked Ti62222STA titanium and Al2024T3 aluminium alloy panels tested under a supersonic transport (SST) spectrum;

d) Crack growth data associated with a surface flaw in 7050-T7451 subjected to a measured RAAF (Royal Australian Air Force) operational load spectrum [74];

e) Crack growth data associated with a small surface flaw in the 1969 F-111 wing test $[74,75]$; and

f) Crack growth data associated with the Aloha accident [76].

As such these examples illustrated that when expressed as per equation (7) crack growth in these examples, which include both cracking in operational aircraft and laboratory tests, was essentially independent of both the material, the microstructure and the flight load spectrum.

\subsection{The importance of the initial crack size}

The initial crack size $\left(a_{i}\right)$ is a key parameter in equation (7). (In contrast we have seen that lead cracks in operational aircraft essentially grow from day one so the term $\mathrm{Bi}$ is often secondary importance for operational aircraft.) For aluminium alloy airframes, the probability distribution associated with the size and nature of the material discontinuities in the airframe is discussed in $[28,30,100,101]$. These authors suggest that the mean size of the material discontinuities is equivalent to a fatigue crack-like size that is typically about $10 \mu \mathrm{m}$ in depth. As shown in [12] this initiating defect size is consistent with the work of Merati [102], where it was reported that the size of initial defects in civil transport aircraft lie in the range 9-29 $\mu \mathrm{m}$, and also with the paper by Schijve [103] where it was reported that the size of initial defects in civil transport aircraft lie in the range 7-30 $\mu \mathrm{m}$.

\subsection{The scatter in the growth of small initial cracks}

Although this section is primarily concerned with the growth of lead cracks in operational aircraft it should be noted that it follows from [26-29] that, for laboratory tests, for a fixed initial crack size the variability in the growth of small cracks is primarily associated with the 
way in which these small cracks interact with the local microstructure. Given that the threshold term can take account of the variability in the growth of cracks of different sizes, [1, $12,27-29,39,40]$, it would appear that the term $\Delta K_{\text {thr }}$ can be thought of as quantifying the way in which small cracks, with a fixed initial size, interact with the local microstructure. In this context it should also be recalled that the operational life of an airframe is primarily determined by the growth of small lead cracks which are generally associated with a small, near zero, fatigue threshold. As such the variability in the growth of lead cracks in operational aircraft is controlled by the probability distribution associated with the size and nature of the material discontinuities in the airframe, rather than by the probability distribution associated with the scatter in the growth of small cracks with a fixed initial size $[28,100,101]$.

\section{DIRECTIONS FOR FUTURE RESEARCH}

\subsection{Conceptual difficulties and conflicting approaches}

Despite the observed lack of an effect of microstructure on the growth of small cracks readers who are knowledgeable of the studies on the micro-structural effects [77, 78], or on computational simulations of micro-structure geometry [79-81], may feel uncomfortable absorbing knowledge. Since that knowledge is based on thorough scientific observation, albeit of the effect on long or non-lead cracks, or simulations, such reticence is both understandable and to be expected. However, the foundation of scientific method was laid down by Sir Francis Bacon almost five hundred years ago, and is encapsulated in the Royal Society motto, "Nullius in verba" - "take nobody's word for it" [82]. The difficulty lies in the need that one should on the one hand acknowledge the science basis of their work, while at the same time recognising that validation via experimental data is a central plank of the scientific method. Nevertheless it may be difficult to accept that the experimental evidence reveals that different microstructures, chemical compositions or yield stresses do not necessarily effect the growth of small cracks. Furthermore, the fact that the experimental data reveals that chemical composition and yield stress do not necessarily effect the growth of long cracks may be even harder to accept.

6.2 Observational science is limited by the methods used to make the phenomenon of interest visible 
Bacon [84] discussed the concept of four types of prejudice, which he describes as "idolae" that are generally rendered in English as "Idols of the Tribe", human prejudices; "Idols of the Cave", personal prejudices; "Idols of the Market Place", confusion caused by language and miscommunication; and "Idols of the Theatre". Of the latter, Bacon says,

"Lastly, there are Idols which have immigrated into men's minds from the various dogmas of philosophies, and also from wrong laws of demonstration..."

Bacon strikes very close to the mark: our scientific approach is frequently "tribal" in that we have personal preferences in the way that we like to interpret our work. Conveying a precise meaning is often difficult, even when expressed through images and mathematics; however, the biggest problem is to overcome dogma, and design experiments and tests that will reveal a true understanding.

Assessment of experimental validity is a well-known feature of experiments in the social sciences area. In the physical sciences the focus is often on the creation of repeatability of measurement, and an error bounds or statistical analysis approach is used to assess variability in the results. Thus the need to create a repeatable test methodology is paramount, so much so that there is sometimes a tendency to overlook the significance of phenomena that are less easy to observe or measure.

In the mechanical testing of materials macroscopic measurements are the easiest to perform, viz: applied force, specimen elongation, crack length, crack opening displacement, etc. The observation of the micro-structure of a sample of material follows in the same vein: the sample is embedded in a carrier, and polished to a high shine to reveal the grain structure. Grain types can then be identified, and various specifics can be measured or counted. This often involves 2D measurements, and the observational task is often limited by the prejudices of the observer, i.e. what seems to be relevant, or what is usually thought to be relevant in such an investigation. That said X-ray computed tomography can now provide a fully 3D equivalent approach, and computational 3D image interpretation software is becoming established in the market place [85]. The algorithms used for geometrical interpretation may still be subject to some restriction, but the process has the potential to enable eventually a holistic assessment of material structure. 
Following failure, the failure surface of the specimen can also be investigated. Whilst crack surfaces generally have an interesting structure classical fracture mechanics based tools ignore that structure and for Mode I failure the fracture surface is considered to be planar Nevertheless, recent studies have used the fractal nature of a fatigue crack surface to gain a better understanding of crack growth and to develop standards for assessing the effect of cracks on operational aircraft $[34,47]$.

Painstaking detailed observation of failure phenomena at the crystal grain boundaries have also been carried out. Numerous textbooks on solid state physics [86, 87] and plasticity [88] discuss atomic dislocations, and the role of alloying impurities in the control of those dislocations. To verify these ideas experimentally requires X-ray or neutron diffraction to measure atomic spacings, and the data obtained represents an assembly of measurements of very large numbers of atoms.

It is not our place to denigrate what is, in reality, extensive and very informative research: the only observation that we wish to make is that such investigations are necessarily incomplete. To focus on the site of one grain boundary or one material flaw is to ignore countless others: a very precise local understanding is built, but the global context is averaged out under the macroscopic measurements.

6.3 Computational models are only as valid as the geometric information they contain

The development of computational models of material structure at the meso-scale is another area in which there has been a lot of attention, particularly in recent years. "Meso-scale" modelling involves the creation of solid mechanical models which mimic the substructure of a material: in this case, it is the modelling of individual grains as separate material domains, or including features or material discontinuities in the structure, where such features are allocated a separate representative material property.

Such models are generally analysed using finite element analysis (FEA), since FEA offers computational robustness, and modern computers are capable of analysing models containing several millions of degrees of freedom within a reasonable time period. Creation of the model poses more difficulty, and there are two major approaches: (i) to find an example of a real material, discover its internal structure through some form of imaging, and reconstruct 
that structure using computer aided design (CAD); or (ii) to develop an algorithm for the arbitrary creation of geometry, and then demonstrate that the geometry so created is sufficiently representative of reality.

The internal structural imaging of a real material is a very difficult problem. Two dimensional images can be obtained readily, but an image analysis method needs to be used to recognise the domain boundaries of the grains; identify the material phase within each grain; and, because at the individual grain length-scale the material is typically anisotropic, identify the orientation. This is not straightforward. In this respect a $2 \mathrm{D}$ representation may not be sufficient. Within the last decade, there have been major advances in X-ray computed tomography (CT). As a result 3D images can now be created without resort to the destructive process of slicing through a material sample and polishing. Image analysis software is in development, not only to identify the material domains, but also material form and alignment recognition. It is conjectured that within a few years, this approach may become applicable for polycrystalline modelling. Current capability to build a CAD geometry differentiating material and voids is certainly possible [88] and points at the potential for polycrystalline modelling in the not too distant future.

The alternative approach, i.e. to define a geometry based on an artificial construction, is certainly possible. Such work is currently almost entirely limited to 2D modelling, and focusses on the construction of a grain structure using algorithms of sowing seed points and then constructing material phase regions using Voronoi tessellation [89-91]. In some ways this approach can be interpreted as a computational analogue of the physical process of metal solidification, since the Voronoi tessellation method forces boundaries at the equi-distant lines between nearest neighbour seed points; however, there are important differences. The first issue is that there should be some basis for the selection of the seed point sites. Assuming a "random" distribution is not enough: choosing random coordinate values leads to a clumpy distribution, which is not representative of reality. Other algorithms are possible, but then the onus is on the modeller to demonstrate the extent to which the representation is sufficiently representative [92]. A second issue is that assuming equi-distance for the boundary lines is essentially the same as assuming an instantaneous initiation and equal growth rates in all directions: in the real solidification process, the initiation of solidification takes place at different sites at different times and at different rates depending on the thermal 
gradient and the crystal alignment. This is, to some extent, what gives rise to grain shapes that cannot be created with Voronoi tessellation.

There is a real need to extend this modelling approach to 3D. Fortunately, in 2D and when extended to three dimensions, a modified version of the Voronoi tessellation method has the potential to capture time lag and anisotropic growth rates [93].

Irrespective of how the $3 \mathrm{D}$ model is created, the nature of the problem is stochastic. As a result to give sensible results, a large number of grains must be modelled. This means that for a cube of material with side lengths of order 10 times the typical grain dimension, the entire model would contain of order 1000 grains. This would be a small model. To have any reasonable definition within a grain, there should be sufficient elements to capture geometry and stress gradients: a sensible minimum number of elements would be of order 100. This means that a the small model would require of order $1000 \times 100$ elements, $\times 3$ degrees of freedom per element. It would be better to model $1,000,000$ or more grains. Fortunately, analysing a model of this size using modern computers is now entirely feasible.

To check the repeatability and validity of results, multiple similar analyses would need to be run. To this end the algorithms used for geometry creation could be tested: different approaches to create seed points will lead to different configurations of grains, and variation levels in grain sizes. Different approaches to modelling grain domains based on a modified Voronoi approach would lead to greater variation in domain shape, and the possibility of anisotropic results. To date the majority of work in this area has not adequately addressed the issues of repeatability and validity. The focus has been on looking for principles in modelling capability, and particular features associated with the creation of the models. A more systematic attempt has been performed [92] to control flaw distribution, but this work looked at void distribution only, rather than grain structure and did not address fatigue crack growth. An important observation derived from this work is that of "emergent" properties. Emergent properties, or "emergence", in the modern sense, relates to the recognition of form or structure arising in a complex model where individual elements in the model do not reflect that structure. Examples of this include the emergent patterns within the Mandelbrot set [94], or cellular automaton [95]. 
6.4 Bulk properties and local properties: interfaces and surfaces

A further important aspect of the micro-scale material is the distinction between "bulk" properties and local properties. Bulk properties apply to large quantities of "pure" material, and while the chemist's view-point might differ from that of the materials scientist or engineer, the essential consideration is that the volume of the material is more significant than the boundary. Harking back to Bacon's Idol of the Tribe, our human experience is so embedded in the macro-scale that our concepts of "surface" or "interface" are often descriptive rather than scientific. For example, when preparing a test specimen, the test methodology [93] will specify a level of surface preparation. The idea is to create a "smooth" surface, and yet no account is taken of the influence of the "smooth" surface on the performance of the specimen, and how this is substantively different to the in-service performance of the unprepared aircraft structure. In practice, there are methods for measuring and quantifying surface roughness [96], and levels of surface roughness can be influenced by both by manufacturing and machining methods and processes, by surface treatment methods [97] and by the in-service operational environment. Indeed, there is currently no study that considers surface effects that reflect the surface conditions associated with lead cracks in an operational structure. This is an important consideration since it is conjectured that this effect may dominate any microstructural related effects.

For a specimen or component for which the bulk is considered homogeneous, the only boundary is the external boundary. Preliminary work considering external surface roughness effects, but not surface conditions that are associated with lead cracks in operational aircraft, on a homogeneous bulk material has recently been submitted for publication [98]. For a polycrystalline material, there are internal surface effects to be considered. Even for very small grain sizes, the grain dimensions are likely to be much greater than the atomic spacing distance, so well within the grain, the material properties can be considered to be "bulk" properties. Towards the boundary of a grain, the regular crystal structure is less strongly imposed, as atoms that are closer to the boundary impose a less regular array of forces on their neighbours than those that are well within the uniformity of structure. The forces and displacements between atoms in the structure are the conduit for the transmission of macrostructural force and displacement within the engineering component; as such, these provide the real physics for which stress and strain are mathematical constructs. Atomic bond force displacement relationships are near linear in performance. Breakdown of this linear 
relationship, and failure of atomic bonds is likewise the paradigm of macroscopic failure; however, macroscopic failure occurs at a much lower value of strain than might be supposed from failure displacement of atomic bonds. The macroscopic concepts of plasticity and creep represent slip of atomic bonds along planes, and reattachment of atoms at new positions [94]. The trigger or control for such a slip lies in the disruption of the regular pattern of atomic bonds, and such irregularities arise from crystal defects, the presence of alloying elements at certain concentrations within the crystal, and the meeting of differently aligned atomic arrays at the grain boundaries.

Models of polycrystalline material assume the boundary to be a piece-wise smooth polygon, and with a zero boundary thickness. This is a mathematical abstraction. In practice, the boundary is the point where pattern of atomic alignment in one grain finishes and the next grain begins. In reality, this is not such a sharply defined feature, since atoms near the interface will try to arrange themselves so as to minimise the atomic bond strain energy, and not lie perfectly in either alignment. The region of modified alignment will thus be of the order of several atomic spaces in width. Furthermore, this boundary will itself move in response to environmental changes. Noting that temperature and concentration of atomic species in solution in the alloy will drive a continual rebalancing of the energy, it should be expected that grains will be slowly but continuously changing form.

This leads to the following questions: Since even "small" cracks are large compared with atomic spacings to what extent can atomic diffusion processes be considered to be a part of the crack development process? In terms of building FEA models of the grain structure, should the interface region be considered to be of finite thickness, and what "bulk" material properties could be allocated to it? Alternatively, what types of atomic modelling analyses should be performed, and how can the results of simulations on an assembly of a finite number of atoms be transferred and interpreted at the continuum mechanics length scale?

This area of investigation is very clearly at the interface between engineering materials and solid-state physics. It may demand a thorough understanding of statistics, a complete re-think of geometry building computer science algorithms and a detailed understanding of both continuum and quantum mechanics. This is a rare skill-set for any individual scientist! 
It follows from [26-29] that for a fixed initial crack size the variability in the growth of small cracks is associated with the way in which these small cracks interact with the local microstructure. Given that the threshold term can take account of the variability in the growth of cracks of different sizes, [1, 12, 27-29, 39, 40], it would appear that the term $\Delta K_{\mathrm{thr}}$ can be thought of as quantifying the way in which small cracks, with a fixed initial size, interact with the local microstructure. In this context it should also be noted that lead cracks determine the operational life of the airframe, and that lead cracks are generally associated with a small, near zero, fatigue threshold. As such the variability in the growth of lead cracks in operational aircraft is controlled by the probability distribution associated with the size and nature of the material discontinuities in the airframe, rather than by the probability distribution connected with the way that small cracks interact with the microstructure of the material $[28,100,101]$.

For aluminium alloy airframes, the probability distribution associated with the size and nature of the material discontinuities in the airframe is discussed in $[28,30,100,101]$. These authors suggest that the mean size of the material discontinuities is equivalent to a fatigue crack-like size that is typically about $10 \mu \mathrm{m}$ in depth. As shown in [12] this initiating defect size is consistent with the work of Merati [102], where it was reported that the size of initial defects in civil transport aircraft lie in the range 9-29 $\mu \mathrm{m}$, and also with the paper by Schijve [103] where it was reported that the size of initial defects in civil transport aircraft lie in the range $7-30 \mu \mathrm{m}$.

We have also noted that crack growth in complex geometries, under variable amplitude loads, representative of aircraft components under operational flight loads, can be predicted to reasonable accuracy using small crack growth data, which can often be closely approximated as a simple Paris crack growth equation. We have noted that the growth of lead cracks in operational aircraft starts from day one of service operation and that the associated crack growth history often conforms to the exponential crack growth model first proposed by the USAF to assess the risk of failure. As a result, the crack growth histories associated with the growth of lead cracks in operational aircraft can often be expressed in a form, which is independent of both the material and the flight load spectrum. However, with the exception of crack growth in bridge steels, the data does not exist to enable us to establish whether this relationship is also true in non-aerospace structures. 


\section{CONCLUSIONS}

The experimental data has shown that even if long cracks in two materials with different microstructures have different $d a / d N$ versus $\Delta K$ curves the corresponding small crack curves can be similar. We have also shown that the experimental data reveals that small cracks in materials with different microstructures, chemical compositions and yield stresses can have similar crack growth rates. As a result of these findings the material community is challenged to address the questions:

Why do the long crack $d a / d N$ vs $\Delta K$ curves associated with a large range of steels with different chemical compositions and yield stresses essentially coincide?

Why do the small crack $d a / d N$ vs $\Delta K$ curves associated with mild steel and the two aerospace quality titanium alloy's essentially coincide?

What is the materials science underpinning the observation that the growth of small naturally occurring cracks in operational aircraft is exponential and that this relationship is independent of the material, microstructure and the flight load spectrum?

What is materials science underpinning the cubic rule that is used by the RAAF to predict the growth of small naturally occurring cracks in aluminium, titanium and steel airframes, i.e. for materials with a range of different microstructures, chemical compositions and yield stresses, in operational aircraft?

The first two questions are particularly important given the current focus on the use of titanium in additive manufacturing. Indeed, they raise the question: Are there instances where the use of cast steels may be a valid alternative to additively manufactured titanium parts?

The latter two questions are particularly important given that exponential crack growth and the cubic rule are widely used to assess cracking in fleet aircraft.

Until such fundamental questions are answered many practitioners will undoubtedly continue to rely on empirical formulations, such as the Hartman-Schijve crack growth equation or the 
cubic rule ${ }^{2}$ [83] which is built into the RAAF F/A-18 Structural Assessment Manual (SAM), the RAAF AP3C (Orion) Structural Repair Assessment Manual (SRAM), and is used to assess cracking in the RAAF Pilatus Porter PC9 fleet. Nevertheless it is understandable if the micro-structure science community, which has invested considerable time and intellect into the study of micro-structural effects in crack development, may find it difficult to accept empirical models, such as the Nasgro equation which is currently the most widely used crack growth equation and is embedded in the commercially available computer codes NASGRO, AFGROW and FASTRAN or the cubic rule, where for small cracks micro-structural effects on the growth have little effect.

We have also seen that atomistic modelling suggests a Paris like crack growth curve and that in one instance the growth of nano scale cracks could be predicted by using the HartmanSchijve long crack representation with the threshold term set to zero.

\section{REFERENCES}

1. Ali K, Peng D, Jones R, Singh Raman RK, Zhao XL, McMillan AJ and Berto F. Crack growth in a naturally corroded bridge steel. Fatigue Fract Eng Mater Struct 2017;40:1117-27.

2. Barsom J M, and Rolfe ST. Fracture and fatigue control in structures: Applications of fracture mechanics. ASTM MNL41. 3rd ed. West Conshohocken, PA: ButterworthHeinemann; 1999.

3. Fisher JW, Mertz DR, Zhong A. Steel bridge members under variable amplitude, long life fatigue loading. NCHRP Project 267. Washington, D.C.: Transportation Research Board; 1983.

4. Chen H, Grodin GY and Driver RG. Fatigue resistance of high performance steel. Sixth International Conference on Short \& Medium Span Bridges, Vancouver, Canada, 2002.

5. Zweraeman FJ and Frank KH. Fatigue damage under variable amplitude loads. Struct Eng 1988;114:67-83.

6. Yan-Ping Liu, Chuan-Yao Chen and Guo-Qing. Fatigue crack growth and control of 14MnNbq welding plates used for bridges. Eng Mechanic-ASCE 2012;138:30-35.

7. Forth SC., James MA., Newman JA. Everett, RA. Jr., and Johnston WM. Jr. Mechanical data for use in damage tolerance analyses. NASA/TM-2004-213503 and ARL-TR-3375. 2004.

8. Stephens RL. Fatigue and fracture toughness of five low carbon cast steels at room or low climate temperature. Carbon and Low Alloy Steel Technical Research Committee. Steel Founders Society of America, Research Report 94A; 1982.

9. Brown CW, King JE, and Hicks MA. Effects of microstructure on long and short crack growth in nickel base superalloys. Met Sci 1984;18:374-80.

\footnotetext{
${ }^{2}$ The cubic rule states that the exponent $\omega$ in Equation (6) is proportional to the cube of the stress field [83].
} 
10. American Society for Testing and Materials (ASTM). Standard Practice for Conducting Force Controlled Constant Amplitude Axial Fatigue Tests of Metallic Materials, ASTM E646, USA, 1988.

11. Ritchie RO, Yu W, Blom AF, Holm DK. An analysis of crack tip shielding in aluminium alloy 2124: A comparison of large, small through-crack and surface fatigue cracks. Fatigue Fract Eng Mater Struct 1987;10:343-63.

12. Jones R. Fatigue crack growth and damage tolerance. Fatigue Fract Eng Mater Struct 2014;37:463-83.

13. Lados DA, Apelian D, Paris PC, Donald JK. Closure mechanisms in Al-Si-Mg cast alloys and long-crack to small-crack corrections. Int J Fatigue 2005; 27: 1463-72.

14. Spiedel MO. Aluminium as a corrosion resistant material, Aluminium Transformation Technology and Application. (Proceedings of the International Symposium at Puerto Madrya, Chubut, Argentina), CA. Pampillo, H. Biloni and DE. Embury, American Society for Metals, Metals Park, Ohio, USA; 1980, p. 613.

15. Boyer HE. Atlas of Fatigue Curves. ASM International; 1985, ISBN: 978-0-87170-2142.

16. Davidson DL, Lankford J. Fatigue crack growth in metals and alloys: mechanisms and micromechanics. Int Mater Rev 1992;37:45-75.

17. Dexter RJ, and Ocel JM. Manual for repair and retrofit of fatigue cracks in steel bridges. US Department of Transportation, Federal Highway Administration Report FHWA-IF13-020; 2013.

18. Molent L, Barter SA, Wanhill RJH. The lead crack fatigue lifing framework. Int J Fatigue 2011, 33, pp. 323-331.

19. Rudd JL. Applications of the equivalent initial quality method. AFFDL-TM-77-58-FBE; 1977.

20. Manning SD, Garver WR, Henslee SP, Norris JW, Pendley BJ, Speaker SM, Smith VD, Yee BGW, Shinozuka M, and Yang YN. Durability Methods Development.

Volume I-Phase I, AFFDL-TR-79.-3118; 1979. http://www.dtic.mil/dtic/tr/fulltext/u2/a087301.pdf

21. Berens AP, Hovey PW, Skinn DA. Risk analysis for aging aircraft fleets. Volume 1: Analysis, WL-TR-91-3066, Flight Dynamics Directorate, Wright Laboratory, Air Force Systems Command, Wright-Patterson Air Force Base; 1991.

22. Wanhill RJH. Characteristic stress intensity factor correlations of fatigue crack growth in high strength alloys: reviews and completion of NLR investigations 1985-1990. NLR-TP-2009-256; 2009.

23. Jones R. and Tamboli D. Implications of the lead crack philosophy and the role of short cracks in combat aircraft. Eng Fail Anal 2013;29:149-66.

24. Mertz D. Steel Bridge Design Handbook: Design for Fatigue. U.S. Department of Transportation, Federal Highway Administration, Publication No. FHWA-IF-12-052 Vol. 12; 2012.

25. Peng D, Jones R, Cairns K, Baker J, McMillan A. Life cycle analysis of steel railway bridges. Theor Appl Fract Mech, https://doi.org/10.1016/j.tafmec.2017.06.023.

26. Larsen JM, Jha SK, Szczepanski CJ, Caton MJ, John R, Rosenberger AH, Buchanan DJ, Golden PJ, Jira JR. Reducing uncertainty in fatigue life limits of turbine engine alloys. Int J Fatigue 2013;57:103-12.

27. Jones R, Huang $\mathrm{P}$ and Peng $\mathrm{D}$. Crack growth from naturally occurring material discontinuities under constant amplitude and operational loads. Int $\mathrm{J}$ Fatigue 2016;91:434-44.

28. Molent L, Jones R. The influence of cyclic stress intensity threshold on fatigue life scatter. Int J Fatigue 2016;82:748-56 
29. Jones R, Molent L, Barter S. Calculating crack growth from small discontinuities in 7050-T7451 under combat aircraft spectra. Int J Fatigue 20133;55:178-82.

30. Barter SA, Molent L and Wanhill RH. Typical fatigue-initiating discontinuities in metallic aircraft structures, Int J Fatigue 2012;41:1-198.

31. Miedlar PC, Berens AP, Gunderson A, and Gallagher JP. Analysis and support initiative for structural technology (ASIST), AFRL-VA-WP-TR-2003-3002.

32. Bouchaud, E. Scaling properties of cracks. J. Phys.: Condens. Matter 9:4319-4344. S0953-8984(97)72446-9; 1997.

33. Mandelbrot BB. Fractal analysis and synthesis of fracture surface roughness and related forms of complexity and disorder. Int J Fract 2006;138:13-17.

34. Jones R, Chen F, Pitt S, Paggi M, Carpinteri A. From NASGRO to fractals: Representing crack growth in metals. Int J Fatigue 2016;82:540-49.36.

35. Carpinteri An, Spagnoli A, A fractal analysis of size effect on fatigue crack growth. Int J Fatigue 2004, 26(2): 125-33.

36. Carpinteri An, Spagnoli A, Vantadori S, A multifractal analysis of fatigue crack growth and its application to concrete. Eng Fract Mech 2010, 77(6): 974-84.

37. Hastings, Philip John. The behaviour of short fatigue cracks in a beta-processed titanium alloy. $\mathrm{PhD}$ Thesis, University of 1989. http://eprints.nottingham.ac.uk/28458/1/352955.pdf

38. Venkateswara Rao KT, Yu W and Ritchie RO. On the behavior of small fatigue cracks in commercial aluminium-lithium alloys. Eng Fract Mech 1988;31:623-35.

39. Lo M, Jones R, Bowler A, Dorman M, Edwards D. Crack growth at fastener holes containing intergranular cracking, Fatigue Fract Eng Mater Struct 2017;40:1664-75.

40. Jones R, Peng D, Singh Raman RK, Pu Huang, Tamboli D, Matthews N. On the growth of fatigue cracks from corrosion pits and manufacturing defects under variable amplitude loading. JOM 2015;67:1385-91.

41. Jones R, Peng D, Pu Huang, Singh Raman RK. Crack growth from naturally occurring material discontinuities in operational aircraft. Procedia Eng 2015;101: 227-34.

42. Tamboli D, Barter S, Jones R, Decoupling of fatigue and corrosion. Proceedings ICAF2017 29th Symposium, Nagoya, Japan, 5th - 9th June, 2017.

43. Lo. M. Interaction of fatigue crack growth and intergranular corrosion in maritime aircraft, PhD Thesis, Department of Mechanical and Aerospace Engineering, Monash University, Clayton, Victoria, Australia, 2016.

44. Lincoln JW, Melliere RA. Economic life determination for a military aircraft, J Aircraft 1999;36:737-42.

45. Zhang K, Yang KV, Lim S, Wub X, Davies CHJ. Effect of the presence of macrozones on short crack propagation in forged two-phase titanium alloys. Int $\mathrm{J}$ Fatigue 2017; 104:1-11.

46. Tan $\mathbf{J}$ and Chen B. Prediction of fatigue life in aluminium alloy (AA7050-T7451) structures in the presence of multiple artificial short cracks In. Theor Appl Fract Mec 2015;78:1-7.

47. Molent L, Spagnoli An, Carpinteri An, Jones R. Using the lead crack concept and fractal geometry for fatigue lifing of metallic structural components. Int J Fatigue 2017;102:214-20.

48. Hartman A and Schijve J. The effects of environment and load frequency on the crack propagation law for macro fatigue crack growth in aluminium alloys. Eng Fract Mech 1970;1:615-31.

49. Liu HW and Liu D. A quantitative analysis of structure sensitive fatigue crack growth in steels. Scr Metall 1984;18:7-12. 
50. Ramsamooj DV. Analytical prediction of short to long fatigue crack growth rate using small- and large-scale yielding fracture mechanics. Int J Fatigue 2003;25:923-33.

51. McEvily AJ, Eifler D, Macherauch E. An analysis of the growth of short fatigue cracks. Eng Fract Mech 1991;40:571-84.

52. Endo M and McEvily AJ. Prediction of the behaviour of small fatigue cracks Mater Sci Eng A 2007;468-470:51-8.

53. Ishihara S, Yoshifuji S, Mcevily Aj, Kawamoto M, Sawai M and Takata M. Study of the fatigue lifetimes and crack propagation behaviour of a high speed steel as a function of the R value. Fatigue Fract Engn Mater Struct 2010;33:294-302.

54. Wang K, Wang F, Cui W, Hayat T and Ahmad B. Prediction of short fatigue crack growth of Ti-6Al-4V. Fatigue Fract Engn Mater Struct 2014;37:1075-86.

55. Jones R, Lo M, Peng D, Bowler A, Dorman M, Janardhana M, Iyyer NS. A study into the interaction of intergranular cracking and cracking at a fastener hole. Meccanica 2015;50:517-32.

56. Jones R, Molent L, Walker K. Fatigue crack growth in a diverse range of materials. Int. J. Fatigue 2012;40:43-50.

57. Newman JC. Jr, (1996) Application of a closure model to predict crack growth in three engine disc materials. Int J Fract 1996;80:193-218.

58. Cadario A, Alfredsson B. Fatigue growth of short cracks in Ti-17: Experiments and simulations. Eng Fract Mech 2007;74:2293-2310.

59. Ritchie RO and Suresh S. The fracture mechanics similitude concept: questions concerning its application to the behavior of short fatigue cracks, Mater Sci Eng 1983;57:L27-L30.

60. Horstemeyer MF, Farkas D, Kim S, Tang T, Potirniche G. Nanostructurally small cracks (NSC): A review on atomistic modeling of fatigue. Int J Fatigue 2010;32:14731502 .

61. Potirniche GP, Horstemeyer MF, Gullett PM, Jelinek B. Atomistic modelling of fatigue crack growth and dislocation structuring in FCC crystals. Proc R Soc A, Math Phys Eng Sci 2006;462:3707-31.

62. Uhnáková A, Machová A, Hora P. 3D atomistic simulation of fatigue behavior of a ductile crack in bcc iron. Int J Fatigue 2011;33:1182-88.

63. Machová A., Pokluda J., Uhnáková A., Hora P. 3D atomistic studies of fatigue behaviour of edge crack (001) in bcc iron loaded in Mode I and II, Int J Fatigue 2014;66:11-19.

64. Chowdhury PB, Sehitoglu S, Rateick RG, Maier HJ. Modeling fatigue crack growth resistance of nanocrystalline alloys. Acta Mater 2013;61:2531-47.

65. Jha SK, John R, Larsen JM. Incorporating small fatigue crack growth in probabilistic life prediction: Effect of stress ratio in Ti-6Al-2Sn-4Zr-6Mo. Int $\mathrm{J}$ Fatigue 2013;51:83-95.

66. Caton MJ, John R, Porter WJ, Burba ME. Stress ratio effects on small fatigue crack growth in Ti-6Al-4V. Int J Fatigue 2012;38:36-45.

67. Mujtaba A, Stelzer S, Brunner AJ, Jones R. Influence of cyclic stress intensity threshold on the scatter seen in cyclic Mode I fatigue delamination growth in DCB tests. Compos Struct 2017;169:138-41.

68. Jones R, Kinloch AJ, Michopoulos JG, Brunner AJ, Phan N. Delamination growth in polymer-matrix fibre composites and the use of fracture mechanics data for material characterisation and life prediction. Compos Struct 2017;180:316-33.

69. Molent L and Gallagher JP. The equivalence of EPS and EIFS based on the same crack growth life data. Int J Fatigue 2015;80:162-70. 
70. Molent L, Barter SA. A comparison of crack growth behaviour in several full-scale airframe fatigue tests. Int J Fatigue 2007;9:1090-99.

71. Miller M., Luthra VK., and Goranson UG. Fatigue crack growth characterization of jet transport structures, Proc. of 14th Symposium of the International Conference on Aeronautical Fatigue (ICAF), Ottawa, Canada, 1987.

72. Bell PD, Creager M. Crack growth analysis for arbitrary spectrum loading. Volume I Results and discussion, Final Report: June 1972 - October 1974, Technical Report AFFDL-TR-74-129, USA, 1974.

73. Phillips EP. Periodic overload and transport spectrum fatigue crack growth tests of Ti62222STA and Al2024T3 sheet. NASA/TM-1999-208995, 1999.

74. Jones R, Molent L, and Pitt S. Crack growth from small flaws. Int J Fatigue 2007;29:1658-67.

75. Fracture Mechanics Volume II - Analysis for Operational Aircraft Usage. FZM-1213647. General Dynamics, 15th July 1973.

76. NTSB. Aircraft Accident Report, Aloha Airlines, Flight 243, Boeing 737-200, N73711, near Maui, Hawaii, April 28, 1988 (Aircraft Accident Report No. NTSB/AAR-89/03), Washington DC, National Transportation Safety Board, 1989.

77. Chowdhury P, Sehitoglu H. Mechanisms of fatigue crack growth - a critical digest of theoretical developments. Fatigue Fract Eng Mater Struct 2016;39:652-74.

78. Morel F, Huyen N. Plasticity and damage heterogeneity in fatigue. Theor Appl Fract Mech 2008;49:98-127.

79. Rodopoulos CA, Chliveros G. Fatigue damage in polycrystals - Part 1: the numbers two and three. Theor Appl Fract Mech 2008;49:61-76.

80. Rodopoulos CA, Chliveros G. Fatigue damage in polycrystals - Part 2: intrinsic scatter of fatigue life. Theor Appl Fract Mech 2008;49:77-97.

81. Simonovski I, Cizelj L. Representative volume element size of a polycrystalline aggregate with embedded short crack, Proc Int Conf Nuclear Energy for New Europe 2007, Portorož, Slovenia, September, 2007.

82. The Royal Society. https://royalsociety.org/about-us/history/ [last accessed 26 August 2017].

83. Molent L., Jones R., (2016) A Stress versus Crack Growth Rate Investigation (aka Stress - Cubed Rule), International Journal of Fatigue, 87, pp, 435-443.

84. Bacon F (1620) Novum Organum. This exists in various translations, or can be found in the original Latin at http://www.thelatinlibrary.com/bacon.html [last accessed 26 August 2017].

85. Simpleware, https://www.simpleware.com/ [last accessed 28 August 2017].

86. Weiss RJ. Solid state physics of metallurgists. Pergamon Press, Oxford; 1963.

87. Friedel J. Dislocations. Pergamon Press, Oxford; 1964.

88. Povstyanoi OYu, Sychuk VA, McMillan A, Rud' VD, Zabolotnyi OV. Metallographic analysis and microstructural image processing of sandblasting nozzles produced by powder metallurgy methods. Powder Metall Met Ceram 2015;54:234-40.

89. Dirichlet GL. Über die Reduktion der positive quadratischen Formen mit drei unbestimmten ganzen Zahlen, J Reine Angew Math 1850;40:209-27.

90. Voronoi G. Nouvelles application des parametrès continus à la théorie des forms quadratiques. J Reine Angew Math 1908;133:97-178.

91. Fortune SJ. A sweepline algorithm for Voronoi diagrams. Algorithmica 1987;2:15374.

92. McMillan AJ. Material strength knock-down resulting from multiple randomly positioned voids. J Reinf Plast Comp 2012;31:13-28. 
93. McMillan AJ. Geometry generation challenges for modelling and analysis of microstructured materials. IOP Conf. Ser: Mater Sci Eng 2015;74 012010

94. Mandelbrot B. Fractal aspects of the iteration of $\mathrm{z} \rightarrow \lambda_{\mathrm{z}}(1-\mathrm{z})$ for complex $\lambda$ and $\mathrm{z}$. Ann N Y Acad Sci 1980;357:249-59.

95. Wolfram S, Packard NH. Two-dimensional cellular automata. J Stat Phys 1985;38:90146.

96. Leach R. Characterisation of areal surface texture. Springer-verlang, Berlin Heidelbert; 2013.

97. Curtis S, de los Rios ER, Rodopoulos CA, Levers A. Analysis of the effects of controlled shot peening on fatigue damage of high strength aluminium alloys. Int $\mathbf{J}$ Fatigue 2003;25:59-66.

98. McMillan AJ, Jones R, Peng D, Chechkin G (TBD) A computational study of the influence of surface roughness on material strength, [submitted to Meccanica, August 2017]

99. Brinckmann S, Van der Giessen E. A fatigue crack initiation model incorporating discrete dislocation plasticity and surface roughness. Int J Fract 2007;148:155-67.

100. White P, Molent L, Barter S. Interpreting fatigue test results using a probabilistic fracture approach. Int J Fatigue 2005;27:752-67.

101. Molent L. Alternative methods for derivation of safe life limits for a 7050-T7451 aluminium alloy structure, Int J Fatigue 2015;74:55-64.

102. Merati A. A study of nucleation and fatigue behavior of an aerospace aluminum alloy 2024-T3. Int J Fatigue 2005;27:33-44.

103. Schijve J. Fatigue life until small cracks in aircraft structures: Durability and damage tolerance. Advanced Structural Integrity Methods for Airframe Durability and Damage Tolerance. Proceedings FAA/NASA International Symposium, Hampton, 1994. NASA Conference Publication 3274. 1994:665-81. 


\section{APPENDIX DEFINITION OF SMALL AND SHORT CRACKS}

The fatigue test standard ASTM E647-13a [10] defines cracks as being small when either 1) their length is small compared to relevant microstructural dimension (a continuum mechanics limitation), 2) their length is small compared to the scale of local plasticity (a linear elastic fracture mechanics limitation), and 3) they are merely physically small $(<1 \mathrm{~mm})$. In this context Appendix X3 of ASTM E647-13a goes on to say: The specific physical dimensions that define small vary with the particular material, geometric configuration, and loadings of interest. On the other had Appendix X3 states defines a crack as being short when only one physical dimension (typically, the length of a through-crack) is small according to the description given above.

To put this definition in perspective it should be noted that, as discussed in [18, 30, 102, 103], the size of typical initiating (small) cracks that are found airframes is generally lies in the range of 3 to approximately $50 \mu \mathrm{m}$ and for aluminium alloy airframes has a mean of approximately $10 \mu \mathrm{m}[18,30,101]$. Consequently, in this paper we will adopt the small crack definition given by Ritchie, Yu, Blom and Holm [11] definition of small, viz: less than 400 microns, rather that contained in either the USAF Damage Tolerant Design Handbook [31] which suggests a significantly larger upper limit or the ASTM E647-13a definition which is less quantitative. 